\title{
The state-of-the-art of soot load estimation in diesel particulate filters: A review
}

\author{
Fuwu $\mathrm{Yan}^{1,2}$, Zhizhou $\mathrm{Cai}^{1,2}$, and Jie $\mathrm{Hu}^{1,2, *}$ \\ ${ }^{1}$ Wuhan University of Technology, Hubei Key Laboratory of Advanced Technology for Automotive \\ Components, China \\ ${ }^{2}$ Hubei Collaborative Innovation Center for Automotive Components Technology, Wuhan, China
}

Keywords: Diesel Particulate Filter (DPF), Particulate Matter (PM), Particulate Number (PN), soot load estimation, soot sensor, on-board diagnosis (OBD).

\begin{abstract}
Diesel particulate filter (DPF), as part of aftertreatment system of internal combustion engine, is considered to be the only feasible way to prominently lessen particle emissions under the requirement of today's strict regulations such as Euro VI, US Tier 3 and China VI. This paper gives a brief introduction of the mechanism and regeneration approaches of DPF, with emphasis on soot load estimation inside the filters, which plays a vital role in formulating regeneration control strategy and ensuring exhaust systemic dependability. Various methods are covered according to different principles, including differential-pressure based methods, which are mostly used nowadays, novel model-based methods and also several newfangled soot sensors, which are progressively developed to meet the increasingly stringent on-board diagnosis (OBD) requirements. The focus of future soot detection and quantitative prediction is to improve accuracy, reliability and robustness, which may necessitate consideration of soot distribution, ash effect, failure identification and fault tolerance handling.
\end{abstract}

\section{Introduction}

Due to the relatively higher heat efficiency and better fuel economy compared to spark ignition (SI) engines, compression ignition (CI) engines running on diesel or bio-diesel fuels are of significance to modern energy saving and emission reduction technology and applied in more fields [1]. As the environmental awareness rises among the international society, emission of diesel engines has become a focus of attention by researchers and enterprises. The main constituents of CI engine emissions include oxides of nitrogen (NOx), oxides of sulphur (SOx), particulate matter $(\mathrm{PM})$, carbon dioxide $\left(\mathrm{CO}_{2}\right)$, carbon monoxide $(\mathrm{CO})$, and unburnt hydrocarbon (HC) [2].

As one of the major concerns, PM causes great harm to environment and human health. Diesel particulates are made up of multiple components, which include the elemental carbon (soot), soluble organic fraction (SOF), sulfates and ash, shown in Figure 1 [3]. According to

\footnotetext{
*Corresponding author: auto_hj@163.com
} 
the experimental data in literature, particle aerodynamic diameter can vary from $20 \mathrm{~nm}$ to $10 \mu \mathrm{m}$ and is greatly influenced by fuel, engine configuration and operating conditions [4]. In fact, it is found that the excessive amounts of nano-level particles can contribute to immune system problems and carcinogen in human being [5]. Therefore, either quantity and mass of particulate are expected to be maintained at an extremely low level to meet the increasingly stringent regulations such as Euro VI, US Tier 3 and China VI [6].

Diesel particulate filter (DPF) technology is recognized as an effective way to cut down PM emissions. Among different DPF solutions, the wall-flow monolith filter is mostly studied due to its excellent filtration efficiency (FE) and acceptable back pressure. Typically, the wall-flow DPF can remove almost all the soot and metallic particles with quite impressive efficiency of $95 \%$ in mass and $99 \%$ in number [7]. This monolith is usually cylindrical ceramic with thousands of fine parallel channels, which are plugged at each end alternatively. Since the soot particle size in diameter is much larger than the porous wall, this structure forces diesel exhaust through the porous substrate walls and then collected inside the wall or deposited on the wall surface by several mechanisms including diffusion, interception, gravity, inertial impaction, etc. [8]. Thereafter soot can be thermal or chemical oxidized and thus PM emissions can be substantially reduced. For better performances in the filters, which include the trapping and oxidation of PM, precise control strategies and accurate regeneration trigger diagnoses are needed. As a key technology of regeneration and diagnosis, the valid prediction of soot loading therefore has become the foremost requirement for successful DPF applications [9].

In this paper, the DPF structure, trapping mechanisms and regeneration technology are briefly introduced. Works and studies about soot load estimation are mainly discussed (including theoretical and experimental methods applied in steady or transient state conditions based on different principles) to seek for a feasible regeneration strategy with an ultimate aim of preventing emission penalties. Meanwhile, related technologies with good prospects for the future OBD requirements such as soot sensors are covered to meet the increasingly stringent emission regulations.

\section{DPF substrate}

To make up for the deficiency of in-engine purification, DPF is widely used to meet the PM legislation as an aftertreatment device. DPF substrate is the key component of the filters to ensure the aftertreatment system performance, which can be characterized by FE, pressure loss, regeneration efficiency, heat and mass transfer characteristics and so on. Generally, the substrate material demands high FE, low pressure loss, high maximum allowable temperature, low thermal expansion coefficient, excellent heat conductivity, chemical stability, thermal stress/shock resistance as well as practicability of catalyst coating. It is noteworthy that a trade-off relationship between high FE and low exhaust resistance is of common occurrence. In addition, aspects such as size, weight and cost are also of significance and ought comprehensively consideration [10].

The DPF substrate materials are mainly divided into three categories: ceramic, metal and composite. Ceramic matrix substates are mostly used, including cordierite, silicon carbide ( $\mathrm{SiC})$, aluminum titanate $\left(\mathrm{Al}_{2} \mathrm{O}_{3} \bullet \mathrm{TiO}_{2}\right)$, mullite, etc. Metal matrix substrates include porous metal, alloy foam, metal fiber felt, etc., and the composite substrate is put forward to compensate for the inherent defects of both materials above, shown in Figure 2 [11]. Presently the most widely studied and applied type is the wall-flow honeycomb ceramic DPF and is often covered with catalyst washcoat. This monolith consists of thousands of parallel square channels along the axial direction with adjacent channels connected by the porous substrate wall and plugged alternatively at opposite ends, shown in Figure 3. 


\section{DPF filtration theories}

At present, the packed bed trapping theory and the fiber trapping theory are commonly used. The former assumes that the filtration medium is composed of several spherical trapping units and the latter considers the trapping units to be cylindrical. The packed bed theory, shown in Figure 4, has been proved to apply better in wall-flow honeycomb ceramic DPF [13]. The spherical collector in the center represents the solid part of the wall, and the space around the collector represents the pore part. As emission particles continuously depositing inside the trapping unit and the diameter of the central trapping unit increases. Macroscopically, the PM will be collected inside the porous substrate wall, which is called deep bed filtration phase. At the end of the deep bed filtration, the particulates will accumulate at the surface of channels and built up a soot layer, which is called cake filtration and in this case no particles are able to enter the wall surface.

The particle collecting mechanisms include inertial collision, interception, Brownian diffusion, gravity deposition, etc., shown in Figure 5. The inertial collision collecting mechanism ignore the size of particle, when the exhaust streamline (locus of the center of particle) curves, particles with greater inertia leave the streamline and collide with the collector. The interception collecting mechanism, on the contrary, ignore the particle mass, as particles of different size flowing along the exhaust streamline, the particle come into contact with the collector surface and be intercepted when the distance between the streamline and the trapping unit is less than or equal to the radius of the particle. The Brownian diffusion always happens due to the thermal motion of gas molecules in exhaust, leaving particles out of the streamline and moving in any direction. The existence of collector will cause a convergent effect and result in particle distribution concentration gradient so that the Brownian diffusion collection can be achieved.

\section{DPF pressure drop}

According to the working principles and mechanisms of DPF, the emission particles (soot, $\mathrm{SOF}$, ash, etc.) collected inside or on wall surface of DPF substrate walls will fill the interspace of filters and significantly reduce the permeability. DPF filtrating processes such as deep bed filtration and cake filtration will lead to the time-dependent increase of DPF pressure drop. Moreover, the installation of DPF will cause engine back pressure, which have a huge impact on engine performance, especially in specific fuel consumption because the engine needs to provide more power to compensate for the loss the increased back pressure brings.

Obviously, there is a relevance between DPF pressure drop and soot loading level. Therefore, pressure drop can be used as a measure of soot load to better formulate DPF control strategy to avoid excessive fuel injections, unsuccessful regenerations and DPF damages. Experimental tests have been conducted by researchers to find out the pressuresoot relationship. As is shown in Figure 6, at the early phase of soot collection which is also known as deep bed filtration, the pressure drop increase rapidly and usually nonlinearly, which results from the sharply decrease of the wall porosity and permeability due to the inside-wall-deposition. The pressure drop curve tends to be linear after the transition from deep bed to cake filtration. This is consistent with many researchers' assumption that the soot layer on the wall surface is evenly distributed and thus provides a smooth and predictable trend of pressure drop.

Moreover, different DPF designs can lead to different engine back pressure and fuel consumption levels [17]. According to the experimental tests results of Mikulic et al., the Acicular Mullite (ACM) DPF caused less engine back pressure than commercially-available cordierite DPF (Cd DPF) and led to a fuel saving of $0.4 \%$ to $2.0 \%$. 
On the other hand, with the development of manufacturing technology, the structural form of wall-flow ceramic filters has been greatly improved and the pressure drop is significantly reduced. In order to improve the filter's capability to accumulate ash, Corning Incorporated put forward the Asymmetric Cell Technology (ACT), shown in Figure 7, to increase the volume and filtration area of the inlet channel to reduce the flow resistance and to cause lower pressure drop [18][19]. The Saint-Gobain also developed a new cell geometry which is called wavy-cell technology, shown in Figure 8. This design also increased the inlet channel volume and filtration area so as to increase ash storage, reduce exhaust flow resistance, and prolong the service life of DPF [20][21].

\section{DPF regeneration}

DPFs perform well in collecting but not eliminating PM. If the particulates were not removed in time, the exhaust resistance will gradually increase. By the time the filter is seriously blocked, the engine back pressure will rise rapidly, which worsens the engine performance thus causes losses of power, economy as well as durability [22]. Therefore, the particulates collected in the filters must be removed or oxidized via certain means so as to restore the filters to a state of low flow resistance. This process is called the DPF regeneration. To work continuously in a long time period, reliable regeneration techniques are required.

According to the difference of reaction mechanism, regenerations can be divided respectively into active and passive types, shown in Figure 9. Active regeneration works by providing an additional energy source to increase the exhaust gas temperature so that PM in the filters could meet the ignition point and burn off. Passive regeneration, on the other hand, lower the activation energy of PM under the influence of catalyst so the particulates will be oxidized at a relatively low temperature [23]. In fact, the exhaust or filter temperature is the most vitally important parameter which influences DPF regeneration because of the highly dependence the soot oxidation rates on temperature, while the regeneration, from another perspective, can be viewed by a dynamic equilibrium between soot capture and soot oxidation.

Except continuous regeneration (catalyst-assisted regeneration, CRT, etc.), under most circumstances the timing of regeneration needs to be judged. It needs to be determined whether the soot load in the filters meet the regeneration demand. The most straightforward way to determine the DPF soot load is to weigh the clean and loaded DPF. However, DPF cannot be disassembled frequently during the actual vehicle operation, indicating this method not feasible. Thus, the indirect prediction and estimation of soot load is of highly importance. In fact, the accuracy of the soot load estimation is one of the key requirements for the successful DPF applications. [24]

\section{Issues in soot load estimation}

Above mentioned DPF regeneration methods, two primary challenges are worth noticing and can be summarized as DPF damage and incomplete DPF regeneration [25]. The former is mainly manifested as DPF local incineration and fracture and the main reason for this result is that the timing of regeneration startup is too late, which leaves the filters overload with soot and leads to the excessive local temperature of DPF in the regeneration process, exceeding the melting point of DPF material and resulting in DPF damage. The latter, on the other hand, is mainly resulted from the premature initiation of regeneration, particulates in the filters are removed in advance without reaching the tolerance limit. If this happens frequently, the tiny pores of porous media in DPF would be blocked off, leading to harmful increase of engine back pressure and would exert bad influence on engine performance. Under actual vehicle driving conditions, neither of these problems are expected. Therefore, 
high accuracy estimation of DPF soot loading is significant in the whole PM emission control strategy.

However, this target is difficult to achieve. Since the soot generation is dependent on the engine operating conditions, massive amount of experimental and emulational data are needed to support building the soot loading model. Meanwhile, due to passive regeneration and the complexity of back pressure at low exhaust flow conditions as well as pressure drop signal hysteresis, it is hard to predict soot load during transient operations [26][27]. Moreover, the ash impact, particle distribution and deposition characteristics also contribute to the complicacy of accurate soot estimating.

To develop a reliable robust soot load estimation method, scholars and researchers at home and abroad conducted extensive research, some of which is introduced as follows, classified by methodological principle.

\section{Traditional soot load estimation methods}

It is impossible to remove DPF and weigh regularly in real driving conditions, which means indirect prediction is almost the only way to estimate soot loading in the filters. Considering multiple mechanisms to the soot load estimation, different mathematical modeling methods, sensors and monitoring indicators are applied. In general, a soot accumulation model based on internal or external parameters, including engine operating conditions, fuel consumption, time elapsed, actual mileage covered and so on, is needed [28]. Some studies using traditional DPF soot loading estimation methods are covered in this section. Sensors based on pressure signals are mostly used. Other types of soot sensors, depending on different experimental designs and setups, are also available and would be introduced in later section in this paper.

\subsection{Pressure-based soot estimating}

Collecting the differential pressure between upstream and downstream of DPF is an effective technology to monitor the soot load [29]. As is shown in Figure 10, the presence of DPF inlet and outlet channels, cake layers and filter walls obstruct the exhaust flow, which manifests as pressure drop through the filters. By analyzing the different components of the total pressure drop in DPF and the corresponding relationship between the pressure drop and the soot load, the soot load can be estimated quantitatively.

Lots of work have been done in order to build the DPF pressure drop model [25] [31] [32]. Generally, under the assumption that all the DPF channels are the same (shown in Figure 11), the pressure drop model could be simplified to the study of one single channel, 6 main source of the DPF pressure drop are to include: pressure drop caused by contraction of inlet exhaust flow and expansion of outlet exhaust flow, pressure drop caused by friction of inlet and outlet exhaust flow, pressure drop caused by wall surface of porous media and pressure drop caused by soot (carbon) layer. The pressure drop characteristics of different loading stages were described by comparing the pressure drop curves of the corresponding soot loading process. The DPF pressure drop model was established based on Darcy's law and friction resistance loss, which could be implemented on the MATLAB/Simulink platform. The estimation results of the model reached a reasonable estimation accuracy.

Assuming the exhaust in the filter is incompressible, the pressure drop equation can be expressed as follows [29]:

$$
\begin{gathered}
\Delta P_{\text {clean }}=\Delta P_{\text {wall }}+\Delta P_{\text {inlet channel }}+\Delta P_{\text {outlet channel }}+\Delta P_{\text {contr\&expan }} \\
=\frac{\mu}{k_{0}} \frac{U \alpha}{4 L} \omega+\frac{2 \mu F}{3 \alpha^{2}} U L+\xi \frac{\rho U^{2}}{2}
\end{gathered}
$$


where $k_{0}$ represents the clean wall permeability, $\mu$ for the exhaust dynamic viscosity, $U$ for the filter channel width, $L$ for the filter length, $F$ for the coefficient of friction and $\xi$ for the contraction/expansion inertia loss coefficient.

As the filter keeps loading, the total pressure drop increases and could be equivalent to the sum of two parts: pressure drop in clean state and pressure drop caused by soot deposition [34].

$$
\begin{gathered}
\Delta P_{\text {total }}=\Delta P_{\text {clean }}+\Delta P_{\text {soot }} \\
\Delta P_{\text {soot }}=\frac{\mu\left(\alpha+w_{S}\right)^{2} Q}{2 V_{\text {trap }}}\left[\frac{w_{S}}{k_{\text {sootwall }}}+\frac{1}{2 k_{\text {sootcake }}} \ln \left(\frac{\alpha}{\alpha-2 w}\right)+\frac{4 F L^{2}}{3\left(\frac{1}{(a-2 w)^{4}}-\frac{1}{\alpha^{4}}\right)}\right]
\end{gathered}
$$

According to Eq. (1)-(3), pressure drop characteristics test can be carried out at clean state and different soot load levels, so as to establish the relationship between $\Delta P_{\text {soot }}$ and exhaust volume flow rate $Q$. In real driving condition, the soot loading level can be determined by subtracting the internal stored clean-state DPF pressure drop from pressure drop calculated in real time by engine control unit. Besides, interpolation can be used for unmeasured intervals and soot-pressure curves.

Rayomand H. Dabhoiwala and John H. Johnson et al. [35] established a pressure drop mathematical model of DPF to provide an approach to real-time computation and measurement of total pressure drop, volumetric flow, exhaust temperature, exhaust gas viscosity, cake and wall permeability. This model assumed that DPF wall permeability was constant, and ignored the influence of soot mass inside the wall and the thickness of cake layer on the width of the DPF inlet channel. By using the simplified mathematical model, the mass of soot deposited on the cake layer could be calculated directly without iterative method and thus indicate triggering of active regeneration and detect filter failures as an OBD tool.

Wang et al. [24] proposed a soot load estimation method based on the linear relationship between exhaust back pressure and deposited particulate quality in a certain period of time under loading condition, supported by analysis of a large number of test data. In the deep bed filtration, although the particle mass was very little, the exhaust back pressure increased sharply because the inside-wall-deposition would significantly decrease the wall porosity, resulting in increase of flow resistance and decrease of permeability. With the increase of collected particulates inside the filter, some particulates began to deposit on the surface of the substrate wall, forming a dense filter cake layer and entering the cake filtration stage where the cake layer is the main filter layer. As the particle mass increased, the exhaust back pressure rose slowly, basically linear with the loading time. The porosity and permeability of the cake layer were closely related to the loading condition and constant with time. Therefore, the pressure drop in the cake filtration stage was much more gradual and predictable than that in the deep bed filtration stage [36]. The pressure drop curves during soot loading process were shown in Figure 12. The results showed that the small flow area was mainly affected by the measurement accuracy of pressure drop, the estimation deviation was large and accuracy needed to be improved especially in this area.

Therefore, it's very important to point out that the accuracy of pressure-based simulation was greatly influenced by the variation of exhaust flow. The soot load for a given pressure drop across the DPF was shown in Figure 13. Inaccuracies at the low volumetric flow conditions were one of the main challenges to the soot load estimation, shown in Figure 14. At low exhaust flows, the pressure drop was low and thus amplifying sensor error or the current pressure differential sensors would find it difficult to accurately capture changes caused by soot loading under these circumstances (typically transient conditions, cold start, etc.) thus alternative methods and improvements were needed.

To make up for this inaccuracy, Singh and Mandarapu [37] utilized the engine out soot model in areas where the volumetric flow dropped below a certain flow threshold. In the meantime, appropriate signal filtering was required to eliminate the noise, shown in Figure 
15. By choosing the volumetric flow threshold and Low Pass Filter (LPF) time constant carefully, the soot estimation signal quality could be prominently improved.

Another challenge to pressure-based estimation method was the impact that soot and ash distribution and partial regeneration brought. As was often the case that soot accumulated in the filters after the partial regeneration. Besides, due to the temperature gradient in the filters, soot was distributed unevenly. Both cases led to the inaccuracy of the soot load estimation.

Meng et al. [38] described the effect of particle characteristics on DPF regeneration performance. An external heat source was used to test the regeneration performance of different particles. Soot with larger specific surface area and high concentration of SOF were proved to have high regeneration efficiency and easy to be burned.

Bermúdez et al. [39] applied a one-dimensional wall-flow DPF model to discussed the dependence of pressure drop, and hence the fuel consumption penalty, on the emitted particle matter distribution (both soot and ash) and the porosity of the particulate layer. Different soot mass distributions along the inlet channels were analyzed via pre-DPF water injection as a technique able to reduce pressure drop so that the baseline DPF was independent of PM loading and their influence on the subsequent soot loading process could be assessed [40]. Figure 16 showed the DPF pressure drop as a function of the particulate layer porosity and the soot mass distribution onset. The results demonstrated that the soot mass on the particulate layer must be moved back as a required condition to reduce the DPF pressure drop.

Wang et al. [41] summarized recent research progress about ash deposited in DPF, analyzing the chemical composition and formation process. It was found that ash was mainly generated from lubricating oil and could not be removed through burning, resulting in the increase of pressure drop shown in Figure 17, and might have negative effect on DPF performance in a long term. However, due to the complexity of DPF regeneration and the uncertainty of ash properties, there were still disagreements on the mechanism of ash distribution process and the effect of distribution form of ash deposited in the DPF channel on the pressure drop. Further investigations on ash physico-chemical property and formation process would be helpful.

Gao et al. [43] established a soot deposition estimation model of DPF considering catalytic regeneration. With the continuous increase of exhaust temperature, the oxidized exhaust particles were correspondingly increased, and catalytic regeneration effectively reduces the particulate matter deposition. Prolonged active regeneration cycle. The soot was mainly distributed in the cake layer, and the deep bed layer took up less, and the soot in the deep bed layer was mainly concentrated in the first layer of the discrete layer, shown in Figure 18. The model was proved to be effective in estimating the soot load and analyzing the soot load distribution.

Zhu et al. [44] simulated the DPF pressure drop characteristics based on different DPF exhaust flow, inlet temperature, particle deposition and distribution types, and emphatically studied the effects of asymmetric cell technology (ACT) as well as ash deposition and distribution form on DPF pressure drop and particle deposition characteristics. The result showed type of particle distribution had great influence on DPF pressure drop and regeneration rate. The particle was not evenly distributed in DPF filters: without considering regeneration, the particle deposition amount decreased first and then increased along the DPF axis direction; along the DPF radial direction, the particle deposition amount at the central axis was the largest, and gradually decreased as it away from the central axis. Besides, when ash distributed layered, it was not conducive to DPF pressure drop and particle deposition characteristics because the particle deposition would be seriously impeded, resulting in rapid increase of DPF pressure drop, which negatively affected engine fuel economy and DPF lifetime.

Besides, to predict the soot loading from DPF pressure drop, new concepts were put forward. Ohyama et al. [36] developed a cordierite-based catalyzed DPF which was no 
catalytic layer coated, for the reason that washcoat was often the origin of unpredictable pressure performance. Then, a modified substrate composition made of catalyst metal was applied in order to guarantee the thermal durability. As traditional catalyzed DPF was hard to accurately estimate the pressure drop, by designing the substrate acted as a catalyst and not using a washcoat, the pressure drop could be linear, shown in Figure 19.

Ogyu et al. [26] shared the view that the main reason to the loss of soot load estimating accuracy was the transient pressure signal hysteresis during deep bed or cake filtering and the fluctuations the exhaust temperature as well as flow rate brought. Filtration layers (FLs) and a new algorithm based on fast Fourier transform (FFT) was then combined to provide an accurate estimating method. The FLs were made of sub-micron ceramic particles of several micrometers thick to prevent the deep bed filtration, shown in Figure 20. The layers helped improving the prediction by eliminating hysteresis from pressure information. Moreover, the new algorithm based on FFT was designed to improve pressure drop linearity and alleviate the impact of exhaust pressure fluctuations. The combination of these techniques reduced the soot amount standard deviation from $1 \mathrm{~g} / \mathrm{L}$ to $0.3 \mathrm{~g} / \mathrm{L}$, compared to current pressure drop measurement system.

In addition, Haralampous [45] et al. provided the derivation of approximate pressure drop for semi-open filter channels (with frontal or rear plugs removed) and used these expressions to predict the pressure drop performance and filtration efficiency of partial failed DPF. Mass and momentum balance equations were solved, which took into account the effect of cake depth. The approximate expressions were validated with 1D model simulations, which covered design configurations such as permeability, length, mass flow rate and soot loading. The results showed about $6 \%$ relative errors for pressure drop and the same absolute errors for filtration efficiency within certain range, shown in Figure 21.

Depcik et al. [46] recalled the history of pressure drop model for particulate filters in their review. Several classical pressure drop models were discussed and compared [33] [47-52]. Most of the equations comprised Darcian and Forchheimer effects through the wall and soot layers, inlet and outlet channel losses, and contraction and expansion losses, but under the assumption of incompressible flow through the filters. In order to improve the universality of these pressure drop models, a thorough re-derivation of dynamic incompressible flow pressure drop equations through soot and wall layer was given. Then a pseudo-compressible model was developed which contained single pressure drop equation and avoided the complexity of the existing models and equations. The accuracy of this model was equal to that of the previous models under isothermal conditions, but it was significantly improved under high soot loadings and non-isothermal conditions.

Although significant achievements have been made, pressure-based soot load estimation still face its limitations and challenges. In addition to disturbance introduced above, sensor tolerance, mass flow rate and so on will also complicate the soot monitoring and predicting. Moreover, engine exhaust gas is a pulsating airflow in nature, which is intensified under diesel transient operating conditions. As a result, the measured values of the pressure sensor are quite noisy, which lead to a significant deviation to determining the soot load and thus lower the reliability of related method using differential pressure sensors, making it difficult to maintain good robustness [53]. Therefore, advanced method improvements are being required.

\subsection{Model-based soot load estimating}

Soot loading models have been developed for years. The current models mainly consider following control parameters: the exhaust back pressure, time, mileage, total consumption of fuel, etc., with multiple input parameter such as engine speed and load, exhaust temperature, volumetric flow rate, engine-out PM and NOx concentration and so on [54]. By the mapping 
and calibrating of DPF software, the soot loading process is monitored in valid and thus a reliable estimating approach for accurate regeneration control strategy as well as the OBD application is provided.

Due to the complexity of internal reactions of DPF during active or passive regeneration, relying solely on pressure drop signals to reflect DPF behavior is far from enough. In order to accurately characterize the loading and regeneration processes of DPF, taking appropriate chemical descriptions into consideration is necessary. Specifically, depending on different engine operation conditions (such as exhaust temperature, exhaust components and corresponding concentrations) and DPF designs (such as catalyst washcoat), soot oxidation can occur within the filter with the help of oxidants $\mathrm{O}_{2}$ and $\mathrm{NO}_{2}$, the former is usually sufficient in concentration in all operating conditions despite its high reaction temperature (over $550{ }^{\circ} \mathrm{C}$ ). By means of cylinder post injection, exhaust pipe fuel injection, electric heater, etc., this can be achieved and mostly utilized in active regeneration DPF systems without catalysts. The latter is much stronger than $\mathrm{O}_{2}$ in oxidizability and play dominant role in most CDPF systems. $\mathrm{NO}_{2}$-based oxidation allows relatively lower reaction temperature at about $260{ }^{\circ} \mathrm{C} \sim 300{ }^{\circ} \mathrm{C}$, which makes it possible to achieve continuously passive regeneration. However, as is well known that the proportion of $\mathrm{NO}_{2}$ in total $\mathrm{NOx}$ in diesel exhaust gas is usually less than 10 percent, a pre-posed diesel oxidation catalyst (DOC) is needed to accomplish the $\mathrm{NO}-\mathrm{NO}_{2}$ conversion.

If elaborate diesel particulate matters are considered, which divided into solid factors (elemental soot and ash), soluble organic fraction (SOF) and sulfate, the weight fraction due to hydrocarbons is close to $50 \%$ [55] and the oxidation of $\mathrm{PM}$ by $\mathrm{O}_{2}$ could be described by a summary reaction:

$$
C_{x} H_{y}+\left[x\left(1-\frac{f_{C O}}{2}\right)+\frac{y}{4}\right] O_{2} \rightarrow x f_{C O} C O+x\left(1-f_{C O}\right) \mathrm{CO}_{2}+\frac{y}{2} H_{2} \mathrm{O}
$$

However, in many studies it is assumed that PM contains only elementary or organic carbon and the reactions taken place in soot cake, ash, washcoat layer and wall can be simplified as:

$$
C+\left(1-\frac{f_{C O}}{2}\right) O_{2} \rightarrow f_{C O} C O+\left(1-f_{C O}\right) \mathrm{CO}_{2}
$$

where $f_{C O}$ is the selectivity coefficient of soot consumed by O2, given by [56][57]:

$$
f_{C O}=\frac{1}{1+A_{f_{C O}} \exp \left(\frac{E_{f_{C O}}}{R T}\right) c_{O_{2}}^{\mu_{\text {inlet }}}}
$$

It can be inferred that $\mathrm{CO}_{2}$ is the preferred product while $\mathrm{CO}$ emission may increase due to its $\mathrm{O}_{2}$ and temperature dependence.

Analogously, diesel particulate matter oxidated by NOx can be drawn as:

$$
\mathrm{C}+\left(2-f_{\mathrm{CO}}\right) \mathrm{NO}_{2} \rightarrow f_{\mathrm{CO}} \mathrm{CO}+\left(1-f_{\mathrm{CO}}\right) \mathrm{CO}_{2}+\left(2-f_{\mathrm{CO}}\right) \mathrm{NO}
$$

As for $\mathrm{CDPF}$, the $\mathrm{NO}-\mathrm{NO}_{2}$ conversion would occur again in precious metal coating area in the filter:

$$
2 \mathrm{NO}+\mathrm{O}_{2} \rightarrow 2 \mathrm{NO}_{2}
$$

The reaction $\mathrm{C}-\mathrm{NO}_{2}$ can also produce small account of $\mathrm{N}_{2}$, though it is much less significant [58]:

$$
\mathrm{C}+\mathrm{NO}_{2} \rightarrow \frac{1}{2} \mathrm{~N}_{2}+\mathrm{CO}_{2}
$$


Rose and Boger [59] proposed a soot loading estimation method based on Matlab/Simulink, which integrated three independent sub-models. Sub-model 1 was a closed-loop model to determine DPF soot loading by pressure drop and volume flow signal; Sub-model 2 was an open-loop model, in which DPF soot loading was determined by the real-world driving mode of the vehicle, which was considered as a function of the vehicle speed and exhaust temperature, shown in Figure 22, and the map was simplified into five different running states. Sub-model 3 was also an open-loop model, which was mainly used to accurately determine the efficiency of DPF active regeneration by taking physical soot oxidation and passive regeneration into account so that to minimize regeneration frequency and regenerating time as much as possible. The method combined two approaches. In one approach, the DPF flow resistance was used to determine its loading state; in the other approach, the open-loop model based on real-world vehicle driving mode (including 5 different states) were programmed and calibrated. This method achieved an accuracy of $+1.5 /-1 \mathrm{~g} / \mathrm{L}$ deviation, shown in Figure 23 .

Tang et al. [61] [62] established theoretical DPF soot load model and tested under the world unified transient cycle (WHTC) test cycle to compensate for the large deviation of the DPF differential pressure sensor under low exhaust flow. The DPF soot load model also consisted of three sub-models: soot transient emission model, soot- $\mathrm{NO}_{2}$ chemical reaction model and soot- $\mathrm{O}_{2}$ chemical reaction model. Simulink was used to integrate the three submodel into a complete simulation model, shown in Figure 24. The model was helpful to improve the accuracy of DPF active regeneration trigger time judgment. However, in the actual operation of diesel engines, the soot accumulation process and regeneration process would be repeated, and the initial soot value during the accumulation process was the remaining during the last regeneration process, which made deviation of soot load estimation becoming larger and larger after a long period of operation. Therefore, reasonable control strategy to prevent the occurrence of above was necessary, so as to meet the practical application requirements of this soot load model.

Furthermore, to precisely predict the soot load and comprehensively consider the characteristics of collection as well as regeneration in the filter, the soot loading amount needs to be calculated by coupling the soot entering the filter, the soot discharged and the soot consumed by oxidizing reactions. The mass balance diagram is shown in Figure 25. and can be formulized as:

$$
\dot{m}_{n e t}=\dot{m}_{\text {in }}-\dot{m}_{\text {oxi }}-\dot{m}_{\text {out }}
$$

where $\dot{m}_{n e t}$ for the net soot accumulation rate in the DPF, $\dot{m}_{\text {in }}$ and $\dot{m}_{\text {out }}$ for the soot mass flow rate at inlet and outlet of the filter, $\dot{m}_{\text {oxi }}$ for the soot oxidation rate.

Konstantinos Boulouchos et al. [60] developed and validated a fast and ideally real-time soot model to calculate raw soot emissions of modern common-rail diesel engines under steady and transient conditions. The model used evolutionary algorithms to parameterize different engine and fuel combinations and then calculated soot emissions, shown in Figure 26. Though the soot emission trend in transient operation could be reproduced, differences between the measured and calculated value cannot be fully captured, which required more in-cylinder process information.

Falcucci et al. [64] proposed a lump-parameter model to study the soot evolution in diesel engine combustion chamber, the soot aggregation, growth and final oxidation in non-catalytic DPF. The model considered the morphology of soot and could predict the characteristics of soot amount, pressure drop, soot layer thickness, permeability, packing density and so on. According to the engine working condition and particle layer characteristics, this model also predicted the temperature change trend real-time in the process of engine regeneration.

An accurate modeling to estimate collected soot using multiple controlling factors and approaches is helpful for active regeneration strategy and OBD diagnostics. The current 
open-loop or the closed-loop estimation models based on differential pressure analysis across the filter have been continuously developed yet still subject to multiple disturbance variations and thus incompetent to satisfy high precision. Additionally, the large number of experimental tests, extensive calibration and the complex chemical reaction analysis that traditional methods required should be improved to comply with the future demand of emission legislation [65].

\section{Up-to-date soot load estimating methods}

Expect for the indirection of measurement, pressure- and model-based methods showed increased errors on transient operations. When pressure measurements are not relied upon estimate soot levels in the filter in low exhaust flow rate conditions, such as at idle and periods of operation during filter regeneration, the DPF control can be sophisticated. In addition, there is also a need to accurately diagnose the health of the DPF and detect conditions which may lead to soot leak from the filter [66]. In order to meet the regulation, more progressive methods and techniques are needed to meet the request of soot load estimating accuracy and regeneration triggering control strategy.

As the fact that active regeneration of DPF is more efficient and is commonly used for DPF. The timing and amount of fuel dosing is crucial in ensuring optimal performance of DPF functions [67]. Current DPF particulate matter detection methods may not likely to be suitable for meeting the stricter requirements [68]. In this respect, Huq and Anwar [67] present an approach of soot measurement using Electrical Capacitance Tomography (ECT). The ECT system, consisted of a capacitance sensor, a Capacitance Measurement Unit (CMU) and a control computer, was able to obtain information about the spatial distribution of a mixture of dielectric materials inside the DPF. Then the permittivity image or soot detection images were mapped onto a square pixel grid, shown in Figure 27, and further, according to the Linear Back Projection (LBP) algorithm [67], transformed into a $2 * 2$ pixel matrix where the change in soot deposition would be reflected. Figure 28. depicted some stages of soot deposition image from the experimental result. The ECT based soot load sensing system could be responsive to the change in particle accumulation thickness.

$\mathrm{Du}$ et al. [53] proposed a method for estimation of the DPF soot load based on a DPF equivalent circuit model, with the diesel engine transient tests based on world harmonized transient cycle (WHTC) test data in the Euro VI standard validated. The theoretical basis for the establishment of the model was shown in Figure 29, the voltage, current, and capacitance of the circuit corresponded respectively to DPF pressure drop, exhaust gas flow, and compressibility of airflow. This electric-fluid analogy relationship allowed the online identification of the flow resistance affected by soot load with measurement parameters (exhaust flow, exhaust temperature and DPF pressure drop) in dual extended Kalman filter (DEKF) [69]. In addition, the relationship between exhaust temperature, resistance and soot load was then established with the least square method and fitting method so that the soot load could be estimated, shown in Figure 30. This method kept the maximal absolute error of $0.2 \mathrm{~g} / \mathrm{L}$ at regeneration timing, without much analysis of chemical reactions and test calibrations.

In short, the newly proposed methods, as one would expect, should overcome the difficulty of accurately online estimating the DPF soot load especially under transient operating conditions and avert the complicatedness of a huge number of experimental tests and analyses of complex chemical reactions which upon most occasions are required in traditional methods.

If extended to raw emissions, neural networks have been widely used to predict diesel engine exhaust emissions in recent years [70]. After determining a certain engine as the research object, bench test can be conducted to find out the effects of diesel engine conditions 
(steady state, transient state), operating environment (temperature, pressure, humidity), fuel quality (biodiesel, different diesel specifications, etc.), lubricating oil quality and other factors on diesel particulate emission characteristics (mass, quantity, size and composition) [71]. The detailed data of the above tests are obtained by engine calibration software and particle emission testing equipment and can be analyzed via time-frequency analysis method such as wavelet transform, short-time Fourier transform and Gabor transform so that the minimum valid data can be dug out from a mass of irregular or random data as the input of neural network model and thus the library of each influencing factor can be established [72]. The structure of the neural network is optimized by global optimal algorithm to improve the model robustness and realize the accurate estimation of engine-out emission of particulate matters [73-75].

Bohari et al. [76] proposed to employ a feedforward neural network to overcome the problem that the map of particulate accumulation requiring a large amount of data and that it was very difficult to apply. The obtained model was used to estimate online the soot loading in the range of $0 \sim 9.32 \mathrm{~g} / \mathrm{L}$ where all of the estimations were of desired practical precision, shown in Figure 31. However, this neural network structure was determined by trial and error. Algorithms were needed to automatically determine the optimum structure for each given problem.

Bose et al. [77] predicted smoke and NOx emissions based on fuzzy logic modeling with the inputs of peak pressure, load, indicated mean effective pressure and so on, shown in Figure 32. It had been seen that the accuracy could be slightly increase with the increase in membership functions but the complexity could increase manifold, shown in Figure 33.

He et al. [78] established a neural network model using parameters such as back pressure and exhaust circulation as input and emission indexes such as NOx and soot emissions as output. The modelling approach used artificial neural networks (ANNs) to represent engine in-cylinder processes, training ANN to approximate computational fluid dynamics (CFD) simulation results of engine. Prior knowledge was incorporated into ANN to improve the modeling accuracy.

Mohammadhassani et al. [79] modeled and optimized NOx and PM emissions of a direct injection diesel engine based on the combination algorithm of ANN and ant colony optimization (ACO), shown in Figure 34. The ACO algorithm was employed to optimize air intake temperatures and the rates of fuel mass injected for different engine operating conditions for the reduction of NOx and soot. The predicted results of soot emissions were compared with experimental ones and good correlation could be obtained at low engine speeds, shown in Figure 35.

By applying the latest interdisciplinary achievements such as mathematics, neural network, signal processing and data mining to the automobile industry, an effective model of emission prediction can be obtained with the minimum data and the prediction ability as well as accuracy of the model can be increased. Besides, the cost of modeling and data collection can be reduced and the robustness of model can be improved, making it potential to generate enormous social and economic benefits.

\section{Soot sensors}

As the OBD regulation for PM emissions is becoming more stringent, sensor techniques based on direct soot monitoring have come into being. Soot sensors are required for OBD to estimate excessive PM emissions downstream of automotive DPF in case of a filter failure. Different types of soot sensors are considered, the mostly used in which is resistive electrode soot sensor, based on conductometric principles. In comparison with other type of sensors, its low cost and inherent simplicity makes it suitable for mass production and use for vehicle OBD purposes [80]. Soot particles deposit on the sensor surfaces, which act as electrodes and 
occur a current increase. Driven by electrophoresis, this continuously increasing of current characterize the more and more soot depositing on the sensor and thus enable to measure the amount of soot in the exhaust [81]. Moreover, the substrate will be periodically heated to remove soot, and the frequency (or the time span) indicates the PM level over the period.

Basically, the soot sensor is operated in a very harsh environment in the exhaust gas downstream from a DPF. The soot sensor must be designed to meet the following requirements: wide operating temperature range, robust to exhaust gas exposures, measurement accuracy, durable to regenerations. Additionally, soot sensor should be sensible enough to distinguish the nuance of soot concentration. For commercial application, size and cost are also needed to be considered.

Great progress has been made to develop soot sensors and interesting results are provided by researchers. Soot sensors are believed to be the new on-board diagnostic tool that will be put into use soon. However, more work should be done to see if soot sensors perform well in variable engine operating conditions. For instance, there is a wide range of adjustable amounts of soot by changing boost and injection pressure and using different kinds of diesel fuel, even at constant engine speed and load [81]. Other physical quantities also have an effect on sensor performance, such as the exhaust gas velocity and the exhaust gas temperature [80]. In addition, as it is found that the overall soot amount and mass are basically independent, recent regulation added particulate number $(\mathrm{PN})$ requirement, the difference between detecting particle mass and number should also be taken into account.

M. Fealner et al. [81], in their investigations, tried to prove whether a conductometric soot sensor is applicable for soot mass determination upstream of a DPF. The signal depended directly on the soot in the exhaust gas flow with respect to both particle number and particle mass. The mechanism of the sensor is showed in Figure 36. Good correlation between sensor data and simultaneous soot analysis was found. After a dead-band (or blind time, when no conductive soot path was formed and the electrical current kept to zero), the slope of the electrical current increased with soot mass or particle number increasing per time interval and showed good linearity in the double-logarithmic representation. This conductometric sensor was improved in the next year [82]. An insulating, thin and dense alumina layer manufactured by the aerosol-deposition-method (ADM) was used to cover the electrode area of a conductometric device and formed a capacitive device, shown in Figure 37. Compared to the conductometric device with a similar interdigital electrodes (IDE) geometry, the capacitive device allowed higher applied DC voltage, which reduced blind time and thus enhanced sensor performance [83][84]. It should be noted that both the supply voltage and the spacing between the electrodes needed to be optimized for the best results by considering both the response time and the element durability [85].

Grondin et al. [86-88] discussed the key parameters that influence the resistive soot sensor response with the aim of building a model to measure soot load. It was found that the sensor response depended on the soot mass and number concentration as well as on the polarization level between the two electrodes. The conductance measured between the electrodes increased as soot deposited. An optimum polarization voltage could be observed to maximize the response. It was attributed to equilibrium between soot bridges creation and their destruction. Respectively caused by polarization effect and combustion at high voltage. Moreover, the conductance value was found clearly linked to the PM mass concentration and composition, while the blind time seemed to be more related with the PN concentration.

Fragkiadoulakis [80] et al. modeled a resistive soot sensor by deposition mechanisms. After analyzing the vehicle test cycle, the parameter range affecting the sensor output was defined and used as inputs. Specific deposition mechanisms included thermophoresis, electrophoresis, convective diffusion, inertial impaction and turbulent impaction, shown in Figure 38. As the electric field intensity and sensor geometry remained constant, the difference of other mainly inputs such as soot concentration, exhaust temperature and exhaust 
gas velocity led to the change of contribution rate of each mechanism component to the total soot deposition. The model could predict the soot sensor behavior in a certain range of working conditions but it still needed attention when applied to transient input data.

Furthermore, the current state-of-art resistive soot sensors have challenges like dead-band and short-circuits sensor failures. Sobocinski et al. [89] in their work used a Silicon Carbide (SiC) MOSFET soot sensor to measure soot concentration in a gas flow, shown in Figure 39. The sensor utilized an additional suspended gate electrode and formed a narrow gap between the two electrodes so that exhaust gas could pass. With the electrophoretic effect generated from electric field between the suspended electrode and common ground, soot was adsorbed on the surface of gate electrode so that the channel conductivity of transistor changed thus affecting source-drain current, which could be obtained as soot-dependent signal. Results showed this sensor, together with the low temperature co-fired (LTCC) package, contributed to the soot detection for diesel exhaust as well as the DPF state for OBD purpose.

Ntziachristos et al. [90] introduced the application of the Pegasor particle sensor (PPS) for the measurement of PM and PN emissions. This sensor, which could be used directly in raw exhaust, was based on the electrical charging of exhaust aerosol and could determinate particle concentration by measuring the charge accumulated on the particles. The signal of the sensor was found linearly to soot mass concentration. After a genetic calibration, the sensor could provide a wide measurement range in transient tests and showed considerable correlation to other devices such as AVL micro soot sensor (MSS) and condensation particle counter (CPC). However, is was not doable for the mass calibration to compare the PPS mass measurement with the PM mass collected in the Constant Volume Sampling (CVS) in case of a DPF vehicle, which put obstacles to estimation accuracy of the PPS.

Tang et al. [91] developed a new leakage current sensor which was installed downstream of DPF to detect failures. The structure of the PM sensor is shown in Figure 40. The leakage current sensor was installed vertically in exhaust pipe. Based on venturi tube principle, the exhaust gas was blocked by the external cannular protection when it goes by, thus arousing differential pressure and forced the exhaust gas to flow through the sensor [92]. The particulate matters in exhaust gas were then ionized and polarized into conductors in the concentration-test zone of the sensor and thus generating leakage current between the electrodes and the shell whose magnitude depended on the PM concentration [93]. The leakage current signal should then be filtered and then converted to voltage signal by an amplification circuit. However, according to experimental results, the signal output was negatively affected by exhaust temperature, contributing to less sensor precision and sensitivity.

In addition, a novel approach used microwaves to monitor directly the soot load and was considered very promising [94]. The microwave-based filter monitoring was showed suitable for either constant or non-steady engine operating conditions [95] [96]. Ragaller et al. [66] explored the potential of measuring soot load via radio frequency (RF) sensors. The RF sensors allowed direct feedback control based on in situ measurements of filter soot levels over a broad range of operating conditions and were expected to contribute to the development of filter management strategies to improve filter durability and reduce engine fuel consumption relative to pressure drop and model based approaches. This method relied on the use of the filter housing as a RF resonant cavity. The accumulation of soot and ash on the filter would alter the dielectric properties of the cavity and thus enabled direct measurement of DPF loading state. The RF measurement approach used two antennas to transmit and receive a radio frequency signal in the particulate filter housing, shown in Figure 41. The RF measurement system showed the potential to extend regeneration intervals and reduce the regeneration duration [97]. Since the calibration of RF sensor must be verified according to actual engine tests, experiments should be performed using Aluminum Titanate and Advanced Cordierite DPFs on both light- and heavy-duty diesel engines. And the result, 
shown in Figure 42, indicated that soot load measurements using the RF sensor to have a high accuracy with respect to the gravimetrically determined loading and was able to provide accurate measurements at traditionally strenuous engine conditions.

In general, most of the soot sensors are still at laboratory stage, with commercial obstacles such as heavy cost and complex technical industry. As a matter of fact, despite the inherit inaccuracy in certain conditions, differential-pressure based approach seems to be more practical and is mostly used in soot load level detecting currently. For further consideration, the optimization of the whole DPF performance requires valid control strategy integrated from engine to aftertreatment system, which should be also coupled with failure diagnosis and fault tolerance control, in view of enhancing robustness.

\section{Summary/Conclusions}

The latest China VI standard is $67 \%$ stricter in PM emissions than China V, which requires all vehicles to be equipped with aftertreatment devices. DPF is believed to be the only feasible way to effectively trap and remove the particulate matters in exhaust and is incrementally used in diesel vehicles to meet the stringent regulation. Though high filtering efficiency could be achieved, today's DPF still face its limitations such as partial unreliable dependence on back pressure and physical clogging, both lead to precarious regeneration behavior and even failure. One successful DPF regeneration is ensured by an integration of multiple technologies, including catalyst skills, substrate skills and proper regeneration managements, etc. In this paper, special importance is addressed in soot load estimation, which is one of the most critical part of regeneration control strategy. Previous literature demonstrated that differential-pressure based method can detect and determine soot load in most cases with respectable dependability. Though a secondary manifestation of soot loading which might bring problems such as time hysteresis and signal drift, it's still the most practical approach and widely used by researchers and enterprises, taken factors as complexity, accuracy, reliability and cost into consideration comprehensively. Other methods with different principles such as alternative model and conductometric soot sensors point out extra directions of soot load estimating development and are likely to provide further application in the future if precision as well as durability and cost are decently dealt with.

To comply the PM or PN legislative limits, better understanding of soot loading and distributing are vitally required. In short, the upcoming emphasis of soot load estimating is to improve the accuracy and system stability as much as possible at a lower cost. Moreover, with an eye to DPF system maintenance, ash loading module should be incorporated into soot models. Sophisticated algorithmic designs of failure diagnosis and fault tolerance are also needed for OBD requirements.

This work was supported by the National Key R\&D Program of China (2017YFC0211203), the Open Funds of National Engineering Laboratory for Mobile Source Emission Control Technology (NELMS2017A08), the Natural Science Foundation of Hubei (2018CFB592) and the Fundamental Research Funds for the Central Universities (2020III038).

\section{References}

[1] Squaiella LF, Martins, CA, Lacava PT. Strategies for emission control in diesel engine to meet Euro VI. Fuel 2013; 104:183-193. https://doi.org/10.1016/j.fuel.2012.07.027.

[2] Tamilselvan P, Nallusamy N, Rajkumar S. A comprehensive review on performance, combustion and emission characteristics of biodiesel fuelled diesel engines. Renewable and Sustainable Energy Reviews 2017;79:1134-1159. https://doi.org/10.1016/j.rser.2017.05.176.

[3] Kittelson DB. Engines and nanoparticles: a review. Journal of Aerosol Science 1998;29(5-6):575588. https://doi.org/10.1016/S0021-8502(97)10037-4. 
[4] Koltsakis G, Konstantinou A, Haralampous O, Samaras Z. Measurement and intra-layer modeling of soot density and permeability in wall-flow filters. SAE International 2006. https://doi.org/10.4271/2006-01-0261.

[5] Bensaid S, Marchisio DL. Modelling of diesel particulate filtration in wall-flow traps. Chemical Engineering Journal 2009;154(1-3):211-218. https://doi.org/10.1016/j.cej.2009.03.043.

[6] Johnson T. Vehicular emissions in review. SAE International 2014. https://doi.org/10.4271/201401-1491

[7] Li C, Mao F, Zhan R, Eakle S. Durability performance of advanced ceramic material DPFs. SAE International 2007. https://doi.org/10.4271/2007-01-0918.

[8] Federica D'Aniello, Rossomando B, Arsie I, Pianese C. Development and experimental validation of a control oriented model of a catalytic DPF. SAE International 2019. https://doi.org/10.4271/2019-01-0985.

[9] Guan B, Zhan R, Lin H, Huang Z. Review of the state-of-the-art of exhaust particulate filter technology in internal combustion engines. Journal of Environmental Management 2015;154:225-258. https://doi.org/10.1016/j.jenvman.2015.02.027.

[10] Iwasaki S, Mizutani T, Miyairi Y, Yuuki K, Makino M. New design concept for diesel particulate filter. SAE International 2011. https://doi.org/10.4271/2011-01-0603.

[11] Adler J. Ceramic diesel particulate filters. International Journal of Applied Ceramic Technology 2005;2(6):429-439. https://doi.org/10.1111/j.1744-7402.2005.02044.x.

[12] Mokhri MA, Abdullah NR, Abdullah SA, Kasalong S, Mamat R. Soot filtration recent simulation analysis in diesel particulate filter (DPF). Procedia Engineering 2012;41:1750-1755. https://doi.org/10.1016/j.proeng.2012.07.378.

[13] Ohara E, Mizuno Y, Miyairi Y. Filtration Behavior of Diesel Particulate Filters. SAE International 2007. https://doi.org/10.4271/2007-01-0921.

[14] Serrano JR, Arnau FJ, Piqueras P. Packed bed of spherical particles approach for pressure drop prediction in wall-flow DPFs (diesel particulate filters) under soot loading conditions. Energy 2013;58:644-654. https://doi.org/10.1016/j.energy.2013.05.051.

[15] Davis CN. Air Filtration. Academic Press. Orlando: FL; 1973.

[16] Orihuela M, Gomez-Martin A, Miceli P. Experimental measurement of the filtration efficiency and pressure drop of wall-flow diesel particulate filters (DPF) made of biomorphic Silicon Carbide using laboratory generated particles. Applied Thermal Engineering 2018;131:41-53. https://doi.org/10.1016/j.applthermaleng.2017.11.149.

[17] Mikulic I, Zhan R, Eakle S. Dependence of fuel consumption on engine backpressure generated by a DPF. SAE International 2010. https://doi.org/10.4271/2010-01-0535.

[18] Aravelli K, Heibel A. Improved lifetime pressure drop management for robust cordierite (RC) filters with Asymmetric Cell Technology (ACT). SAE International 2007. https://doi.org/10.4271/2007-01-0920.

[19] Heibel A, Bhargava R. Advanced diesel particulate filter design for lifetime pressure drop solution in light duty applications. SAE International 2007. https://doi.org/10.4271/2007-01-0042.

[20] Bardon S, Bouteiller B, Bonnail N. Asymmetrical channels to increase DPF Lifetime. SAE International 2004. https://doi.org/10.4271/2004-01-0950.

[21] Briot A, Carranza F, Girot P, Bardon S. Minimizing filter volume by design optimization. SAE International 2007. https://doi.org/10.4271/2007-01-0657.

[22] Gardner T, Yetkin A, Shotwell R. Evaluation of a DPF regeneration system and DOC performance using secondary fuel injection. SAE International 2009. https://doi.org/10.4271/2009-01-2884.

[23] Yu M, Luss D, Balakotaiah V. Regeneration modes and peak temperatures in a diesel particulate filter. Chemical Engineering Journal 2013;232:541-554. https://doi.org/10.1016/j.cej.2013.08.006.

[24] Wang D, Liu Z, Han Y. Experimental study on pressure drop performance and regeneration safety of diesel particulate filter. ICEICE 2011, Wuhan, China; 2011.

[25] Athanasios G Konstandopoulos. Fundamental studies of diesel particulate filters: transient loading, regeneration and aging. SAE International 2000. https://doi.org/10.4271/2000-01-1016.

[26] Ogyu K, Yamakawa T, Ishii Y. Soot loading estimation accuracy improvement by filtration layer forming on DPF and new algorithm of pressure loss measurement. SAE International 2013. https://doi.org/10.4271/2013-01-0525.

[27] Oliveira LM, Savvidis D, Sr MP. Controlling particulate matter emissions in vehicles using different strategies under the heavy-duty test cycle. SAE International 2012. https://doi.org/10.4271/2012-01-0885.

[28] Chen X, Kumar A, Klippstein D, Stafford R, Su CS, Yuan Y, Zokoe J, McGinn P. Development and demonstration of a soot generator integrated bench reactor. SAE International 2014. https://doi.org/10.4271/2014-01-1589.

[29] Konstandopoulos A. Flow resistance descriptors for diesel particulate filters: definitions, measurements and testing. SAE International 2003. https://doi.org/10.4271/2003-01-0846. 
[30] Deng Y. Investigations on the temperature distribution of the diesel particulate filter in the thermal regeneration process and its field synergy analysis. Applied Thermal Engineering 2017;123:92102. https://doi.org/10.1016/j.applthermaleng.2017.05.072.

[31] Evdoxia A. Kladopoulou, Yang S. A study describing the performance of diesel particulate filters during loading and regeneration-a lumped parameter model for control applications. SAE International 2003. https://doi.org/10.4271/2003-01-0842.

[32] Masoudi M, Athanasios G Konstandopoulos. Validation of a model and development of a simulator for predicting the pressure drop of diesel particulate filters. SAE International 2001. https://doi.org/10.4271/2001-01-0911.

[33] Masoudi M, Heibel A, Paul M Then. Predicting pressure drop of wall-flow diesel particulate filters--theory and experiment. SAE International 2000. https://doi.org/10.4271/2000-01-0184.

[34] Choi S, Kyeong L. Detailed investigation of soot deposition and oxidation characteristics in a diesel particulate filter using optical visualization. SAE International 2013. https://doi.org/10.4271/2013-01-0528.

[35] Rayomand H Dabhoiwala, John H Johnson, Jeffrey D Naber, Susan T Bagley. A methodology to estimate the mass of particulate matter retained in a catalyzed particulate filter as applied to active regeneration and on-board diagnostics to detect filter failures. SAE International 2008. https://doi.org/10.4271/2008-01-0764.

[36] Ohyama N, Nakanishi T, Daido S. New concept catalyzed DPF for estimating soot loadings from pressure drop. SAE International 2008. https://doi.org/10.4271/2008-01-0620.

[37] Singh N, Mandarapu S. DPF soot estimation challenges and mitigation strategies and assessment of available DPF technologies. SAE International 2013. https://doi.org/10.4271/2013-01-0838.

[38] Meng Z, Chen C, Li J. Particle emission characteristics of DPF regeneration from DPF regeneration bench and diesel engine bench measurements. Fuel 2020;262. https://doi.org/10.1016/j.fuel.2019.116589.

[39] Bermúdez V, Serrano JR, Piqueras P, Sanchis EJ. On the impact of particulate matter distribution on pressure drop of wall-flow particulate filters. Applied Sciences 2017;7(3):234. https://doi.org/10.3390/app7030234.

[40] Bermúdez V, Serrano JR, Piqueras P, García-Afonso O. Pre-DPF water injection technique for pressure drop in loaded wall-flow diesel particulate filters. Applied Energy 2015;140:234-245. https://doi.org/10.1016/j.apenergy.2014.12.003.

[41] Wang H, Ge Y, T J. Ash deposited in diesel particular filter: a review. Energy Sources, Part A: Recovery, Utilization and Environmental Effects 2019;41(18):2184-2193. https://doi.org/10.1080/15567036.2018.1550539.

[42] Fang J, Meng Z, Li J. The influence of ash on soot deposition and regeneration processes in diesel particular filter. Applied Thermal Engineering 2017; 124:633-640. https://doi.org/10.1016/j.applthermaleng.2017.06.076.

[43] Gao Y, Liu H, Chen W, Fu T, Fang M, Li J, Research on soot filtration and pressure drop characteristics of DPF. Proceedings of SAE-China Congress 2016: Selected Papers, Shanghai, China; 2016. https://doi.org/10.1007/978-981-10-3527-2_6.

[44] Zhu, Y. Numerical simulation of pressure-drop and soot particle accumulation performance of a diesel engine DPF. Transactions of CSICE (Chinese Society for Internal Combustion Engines) 2017;35(6):538-547. https://doi.org/10.16236/j.cnki.nrjxb.201706075.

[45] Haralampous O, Kontzias T. Approximate pressure drop and filtration efficiency expressions for semi-open wall-flow channels. Canadian Journal of Chemical Engineering 2014;92(9):15171525. https://doi.org/10.1002/cjce.21982.

[46] Depcik C, Spickler B, Gaire A. Revisiting the single equation pressure drop model for particulate filters. SAE International 2018. https://doi.org/10.4271/2018-01-0952.

[47] Edward J Bissett. Mathematical model of the thermal regeneration of a wall-flow monolith diesel particulate filter. Chemical Engineering Science 1984;39(7-8):1233-1244. https://doi.org/10.1016/0009-2509(84)85084-8.

[48] Athanasios G Konstandopoulos, John H. Johnson. Wall-flow diesel particulate filters-their pressure drop and collection efficiency. SAE International 1989. https://doi.org/10.4271/890405.

[49] Cornelius N Opris, John H Johnson. A 2-D computational model describing the flow and filtration characteristics of a ceramic diesel particulate trap. SAE International 1998. https://doi.org/10.4271/980545.

[50] Suresh A, Khan A, John H. Johnson. An experimental and modeling study of cordierite traps pressure drop and permeability of clean and particulate loaded traps. SAE International 2000. https://doi.org/10.4271/2000-01-0476.

[51] Hashimoto S, Miyairi Y, Hamanaka T, Matsubara R, Harada T, Miwa S. SiC and cordierite diesel particulate filters designed for low pressure drop and catalyzed, uncatalyzed systems. SAE International 2002. https://doi.org/10.4271/2002-01-0322.

[52] Gaiser G, Mucha P. Prediction of pressure drop in diesel particulate filters considering ash deposit and partial regenerations. SAE International 2004. https://doi.org/10.4271/2004-01-0158. 
[53] Du Y, Hu G, Xiang S, Zhang K, Liu H, Guo F. Estimation of the diesel particulate filter soot load based on an equivalent circuit model. Energies 2018;11(2):472. https://doi.org/10.3390/en11020472.

[54] Kim YW, Nieuwstadt MV, Stewart G, Pekar J. Model predictive control of DOC temperature during DPF regeneration. SAE International 2014. https://doi.org/10.4271/2014-01-1165.

[55] Neri G, Bonaccorsi L, Donato A, Milone C, Musolino MG, Visco AM. Catalytic combustion of diesel soot over metal oxide catalysts. Applied Catalysis B: Environmental 1997;11(2):217-231. https://doi.org/10.1002/chin.199718022.

[56] Neeft J, Nijhuis TX, Smakman E,Makkee M, Moulijn JA. Kinetics of the oxidation of diesel soot. Fuel 1997;76:1129-1136. https://doi.org/10.1016/S0016-2361(97)00119-1.

[57] Konstandopoulos AG, Kostoglou M. Reciprocating flow regeneration of soot filters. Combustion and Flame 2000;121:488-500. https://doi.org/10.1016/S0010-2180(99)00156-X.

[58] Stanmore BR, Tschamber V, Brilhac JF. Oxidation of carbon by NOx, with particular reference to $\mathrm{NO}_{2}$ and $\mathrm{N}_{2} \mathrm{O}$. Fuel 2008;87:131-146. https://doi.org/10.1016/j.fuel.2007.04.012.

[59] Rose D, Boger T. Different approaches to soot estimation as key requirement for DPF applications. SAE International 2009. https://doi.org/10.4271/2009-01-1262.

[60] Konstantinos Boulouchos. A phenomenological mean value soot model for transient engine operation. MTZ Worldwide 2008;69(7-8):58-65. https://doi.org/10.1007/BF03227906.

[61] Tang J, Li G, Wang Z. Construction and experiment of DPF soot loading model. Transactions of CSICE (Chinese Society for Internal Combustion Engines) 2015;33(1):51-57. https://doi.org/10.16236/j.cnki.nrjxb.201501008.

[62] Bai S, Tang J, Wang G, Li G. Soot loading estimation model and passive regeneration characteristics of DPF system for heavy-duty engine. Applied Thermal Engineering 2016;100:1292-1298. https://doi.org/10.1016/j.applthermaleng.2016.02.055.

[63] Huang T, Zhu Y, Ran Y. Calibration of a mass balance based soot load estimation model for diesel particulate filter. IFAC-Papers OnLine 2018;51(31):362-365. https://doi.org/10.1016/j.ifacol.2018.10.074.

[64] Giacomo Falcucci. A lumped parameter model for diesel soot morphology evaluation and emission control. Proceedings of the Institution of Mechanical Engineers. Part D: Journal of Automobile Engineering 2012;226(D7):987-998. https://doi.org/10.1177/0954407011434251.

[65] Hoepfner A, Roduner CA. PM sensor based on-board diagnosis of particulate filter efficiency. SAE International 2013. https://doi.org/10.4271/2013-01-1515.

[66] Ragaller P, Sappol A, Bromberg L. Particulate filter soot load measurements using radio frequency sensors and potential for improved filter management. SAE International 2016. https://doi.org/10.4271/2016-01-0943.

[67] Huq R, Anwar S. An electrical capacitance based measurement method for soot load estimation in a diesel particulate filter. IFAC Proceedings Volumes 2014;47(3):8463-8468. https://doi.org/10.3182/20140824-6-ZA-1003.00920.

[68] Husted H, Roth G,Nelson S, Hocken L, Fulks G, Racine D. Sensing of particulate matter for onboard diagnosis of particulate filters. SAE International 2012. https://doi.org/10.4271/2012-010372 .

[69] Xiong R, Sun F, Chen Z. He H. A data-driven multi-scale extended Kalman filtering based parameter and state estimation approach of lithium-ion olymer battery in electric vehicles. Applied Energy 2014;113:463-476. https://doi.org/10.1016/j.apenergy.2013.07.061.

[70] Domínguez-Sáez A, Rattá G, Barrios C. Prediction of exhaust emission in transient conditions of a diesel engine fueled with animal fat using Artificial Neural Network and Symbolic Regression. Applied Energy 2018;149:675-683. https://doi.org/10.1016/j.energy.2018.02.080.

[71] Dharma S, Hassan HM, Ong CH. Experimental study and prediction of the performance and exhaust emissions of mixed Jatropha curcas-Ceiba pentandra biodiesel blends in diesel engine using artificial neural networks. Journal of Cleaner Production 2017;164:618-633. https://doi.org/10.1016/j.jclepro.2017.06.065.

[72] Rahimi molkdaragh R, Jafarmadar S, Khalilaria H. Prediction of the performance and exhaust emissions of a compression ignition engine using a wavelet neural network with a stochastic gradient algorithm. Energy 2018;142:1128-1138. https://doi.org/10.1016/j.energy.2017.09.006.

[73] Nelson SA, Filipi ZS, Assanis DN. The use of neural nets for matching fixed or variable geometry compressors with diesel engines. Journal of Engineering for Gas Turbines and Power 2003;125(2):572-579. https://doi.org/10.1115/1.1563239.

[74] Deng J, Bastian M, Stobart R. Particulate matter prediction in both steady state and transient operation of diesel engines. Proceedings of the Institution of Mechanical Engineers Part D Journal of Automobile Engineering 2012;226(2):260-274. https://doi.org/10.1177/0954407011418029.

[75] Roy S, Banerjee R, Bose P K. Performance and exhaust emissions prediction of a CRDI assisted single cylinder diesel engine coupled with EGR using artificial neural network. Applied Energy 2014;119(15):330-340. https://doi.org/10.1016/j.apenergy.2014.01.044. 
[76] Bohari AR, Mizuno N. Estimation of particulate loading in diesel particulate filter using neural network. JSME International Journal. Series C 1998;41(4):792-797. https://doi.org/10.1299/jsmec.41.792.

[77] Bose N, Kumar N S. Prediction of engine emissions through fuzzy logic modeling. International Conference on Conference on Computational Intelligence and Multimedia Applications, ICCIMA 2007. Sivakasi, Tamil Nadu, India; 2007.

[78] He Y, Rutland CJ. Application of artificial neural networks in engine modelling. International Journal of Engine Research 2004;5(4):281-296. https://doi.org/10.1243/146808704323224204.

[79] Mohammadhassani J, Dadvand A, Khalilarya Sh. Prediction and reduction of diesel engine emissions using a combined ANN-ACO method. Applied Soft Computing 2015;34:139-150. https://doi.org/10.1016/j.asoc.2015.04.059.

[80] Fragkiadoulakis P, Geivanidis S, Samaras Z. Modeling a resistive soot sensor by particle deposition mechanisms. Journal of Aerosol Science 2018;123:76-90. https://doi.org/10.1016/j.jaerosci.2018.06.005.

[81] Feulner M, Hagen G, Müller A. Conductometric sensor for soot mass flow detection in exhausts of internal combustion engines. Sensors (Basel, Switzerland) 2015;15(11):28796-28806. https://doi.org/10.3390/s151128796.

[82] Hagen G, Feulner M, Werner R, Schubert M. Capacitive soot sensor for diesel exhausts. Sensors and Actuators B: Chemical 2016;236:1020-1027. https://doi.org/10.1016/j.snb.2016.05.006.

[83] Bartscherer P, Moos R. Improvement of the sensitivity of a conductometric soot sensor by adding a conductive cover layer. Journal of Sensors and Sensor Systems 2013;2(2):95-102. https://doi.org/10.5194/jsss-2-95-2013.

[84] Kondo A, Yokoi S, Sakurai T, Nishikawa S. New particulate matter sensor for on board diagnosis. SAE International 2011. https://doi.org/10.4271/2011-01-0302.

[85] Takeyuki Kamimoto. A review of soot sensors considered for on-board diagnostics application. International Journal of Engine Research 2017;18(5-6):631-641. https://doi.org/10.1177/1468087416678499.

[86] Grondin D, Breuil P, Viricelle JP, Vernoux P. Development of a particulate matter sensor for diesel engine. Procedia Engineering 2015;120:1237-1240. https://doi.org/10.1016/j.proeng.2015.08.838.

[87] Grondin D, Geara S, Breuil P. Influence of electrodes polarization on the response of resistive soot sensor. Procedia Engineering 2016;168:31-34. https://doi.org/10.1016/j.proeng.2016.11.124.

[88] Grondin D, Westermann A, Breuil P, Viricelle JP, Vernoux P. Influence of key parameters on the response of a resistive soot sensor. Sensors and Actuators B: Chemical 2016;236:1036-1043. https://doi.org/10.1016/j.snb.2016.05.049.

[89] Sobocinski M, Bilby D, Kubinski D. SiC MOSFET soot sensor in a co-fired LTCC package. Procedia Engineering 2016;168:27-30. https://doi.org/10.1016/j.proeng.2016.11.123.

[90] Ntziachristos L, Amanatidis S, Samaras Z. Application of the pegasor particle sensor for the measurement of mass and particle number emissions. SAE International 2013. https://doi.org/10.4271/2013-01-1561.

[91] Tang D, Zhao R, Wang S, Wang J, Ni L, Chen L. The simulation and experimental research of particulate matter sensor on diesel engine with diesel particulate filter. Sensors and Actuators A: Physical 2017;259:160-170. https://doi.org/10.1016/j.sna.2017.03.036.

[92] Rodio MG, Congedo PM. Robust analysis of cavitating flows in the Venturi tube. European Journal of Mechanics B/Fluids 2014;44:88-99. https://doi.org/10.1016/j.euromechflu.2013.11.002.

[93] Xu X, Zheng C, Yan P, Zhu W. Effect of electrode configuration on particle collection in a hightemperature electrostatic precipitator. Separation and Purification Technology 2016;166:157-163. https://doi.org/10.1016/j.seppur.2016.04.039.

[94] Fischerauer G, Förster M, Moos R. Sensing the soot load in automotive diesel particulate filters by microwave methods. Measurement Science and Technology 2010;21(3):035108. https://doi.org/10.1088/0957-0233/21/3/035108.

[95] Feulner M, Seufert F, Muller A, Hagen G, Moos R. Influencing parameters on the microwavebased soot load determination of diesel particulate filters. Topics in Catalysis 2017;60(3-5):374380. https://doi.org/10.1007/s11244-016-0626-7.

[96] Sappok A, Ragaller P, Bromberg L. Real-time engine and aftertreatment system control using fast response particulate filter sensors. SAE International 2016. https://doi.org/10.4271/2016-01-0918

[97] Sappok A, Bromberg L. Radio frequency diesel particulate filter soot and ash level sensors: enabling adaptive controls for heavy-duty diesel applications. SAE International 2014. https://doi.org/10.4271/2014-01-2349. 


\section{Figure captions}

Figure 1: Typical diesel emissions of particulate matter.

Figure 2: Typical diesel emissions of particulate matter SEM images of different DPF substrate materials.

Figure 3: The example of wall-flow monolith honeycomb design (left) and the detailed view inside (right).

Figure 4: Spherical unit cell trapping theory.

Figure 5: DPF trapping mechanisms.

Figure 6: Pressure drop of the wall-flow bioSiC filters.

Figure 7. Standard and asymmetric cell technology (ACT) designs.

Figure 8. Standard square cell geometry and wavy cell geometry of honeycomb structures.

Figure 9. DPF regeneration approaches.

Figure 10. Geometry of inlet and outlet channels of honeycomb ceramic wall-flow monolith .

Figure 11. Loaded DPF channel section

Figure 12. Pressure drop behavior of DPF.

Figure 13. Pressure Drop, Volumetric Flow and Soot Load in the DPF Relationship.

Figure 14. DPF Pressure Drop Based Soot Load Estimate; 90\% Error Bands as a Function of Exhaust Volume Flow.

Figure 15. DPF Restriction Signal Processing.

Figure 16. DPF pressure drop as a function of the particulate layer porosity and the soot mass distribution onset imposing a linear soot mass distribution.

Figure 17. DPF pressure drop as a function of the particulate layer porosity and the soot mass distribution onset imposing a linear soot mass distribution.

Figure 18. Schematic of deep bed slabs.

Figure 19. (a) Influence of washcoat amount on pressure drop; (b) Comparison of estimation accuracy of linear DPF(LDPF) and CDPF.

Figure 20. Schematic image of concept of filtration layers technology.

Figure 21. Correlation of approximate filtration efficiency to (a) approximate filtration efficiency filtration efficiency error and (b) pressure drop error.

Figure 22. Soot map of a typical LDD engine determined with an AVL Micro Soot Sensor.

Figure 23. Results for the combination of all 3 models (soot $\mathrm{CM}$ ) /positive values represent underestimation.

Figure 24. Simulation model of DPF soot loading.

Figure 25. Diagram of mass balance based soot load estimation.

Figure 26. (a) Emissions in steady state (engine one, reference fuel); (b) Emissions in steady state (engine one, fuel two); (c) Emissions in transient state at $1250 \mathrm{rpm}, \Delta \mathrm{t}=0.5 \mathrm{~s}$; (d) Emission s in transient state at $2000 \mathrm{rpm}, \Delta \mathrm{t}=0.5 \mathrm{~s}$.

Figure 27 . A $16 * 16$ square pixel grid used to display the permittivity distribution image.

Figure 28. (a) DPF 0 fill; (b) DPF 25\% fill; (c) DPF 50\% fill; (d) DPF 75\% fill.

Figure 29. Diesel particulate filter equivalent circuit model.

Figure 30. Online estimation process of the soot load.

Figure 31. Precision of estimated particulate loading.

Figure 32. System inputs and outputs.

Figure 33. Regression analysis for prediction of smoke.

Figure 34. (a) Simple structure of the used ANN; (b) Detailed structure of the used ANN.

Figure 35. Comparison between the predicted and measured soot emission for different operating conditions.

Figure 36. Typical resistive sensor signal and phases of operation.

Figure 37. (a) Sketch of the interdigital electrode design (top view) ; (b) Schematic cross-section of the sensor setup for the conductometric type principle (soot deposition on the sensor surface led to a decreased resistance between the electrodes); (c) Schematic cross-section of the sensor setup for the capacitive type principle (soot deposition on the sensor surface affected the electrical field distribution and therefore affected the capacitance).

Figure 38. The soot deposition model of the sensor.

Figure 39. Schematic cross-section of the SiC MOSFET soot sensor.

Figure 40. Dimensional structure of the leakage current sensor.

Figure 41. RF measurement system configuration.

Figure 42. (a) RF soot load measurement for the heavy-duty engine setup; (b) Comparison of gravimetric and SLP soot load estimation for heavy duty uncontrolled regeneration tests. At low flow conditions, such as those during idle, accurate pressure drop measurements were unavailable. 


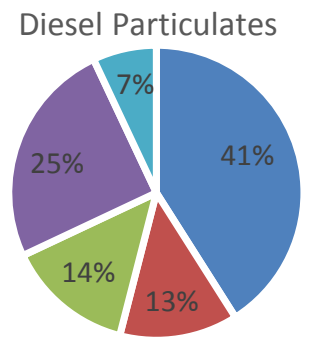

- Soot

- Sulphate and water

- Unburned fuel SOF
- Metal ash and others

- Unburnt lubricating oil SOF

Figure 1: Typical diesel emissions of particulate matter.

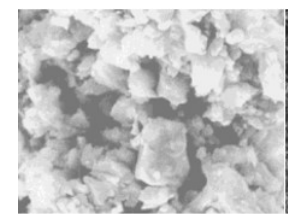

Cordierite

Silicon $\mathrm{Carbide}(\mathrm{SiC}) \quad$ Aluminum Titanate

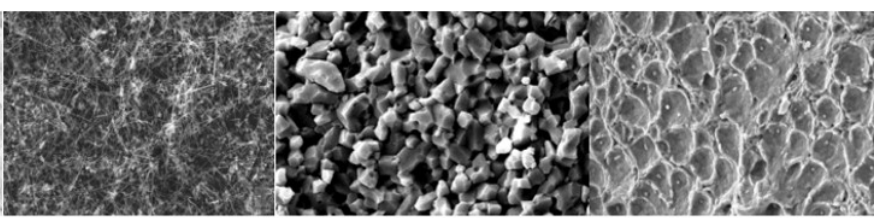

Alloy Foam materials [10].

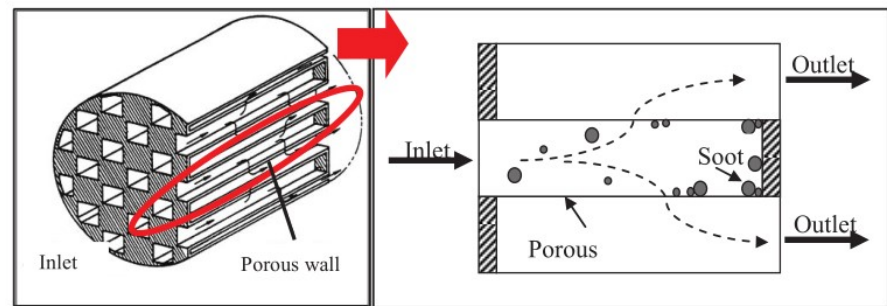

Figure 3: The example of wall-flow monolith honeycomb design (left) and the detailed view inside (right)

a)

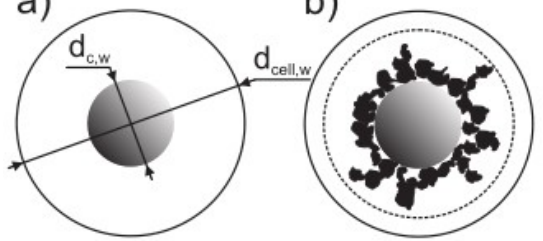

C)

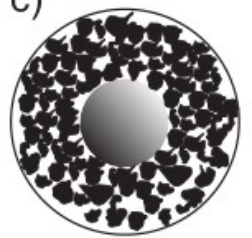

Figure 4: Spherical unit cell trapping theory [14]. 

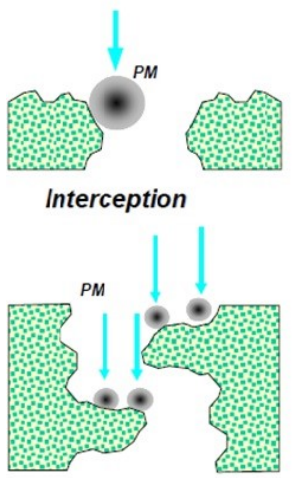

Inertia

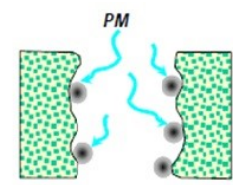

Diffusion

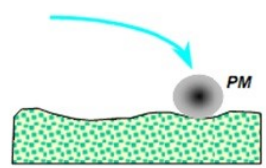

Gravity

Figure 5: DPF trapping mechanisms [15].

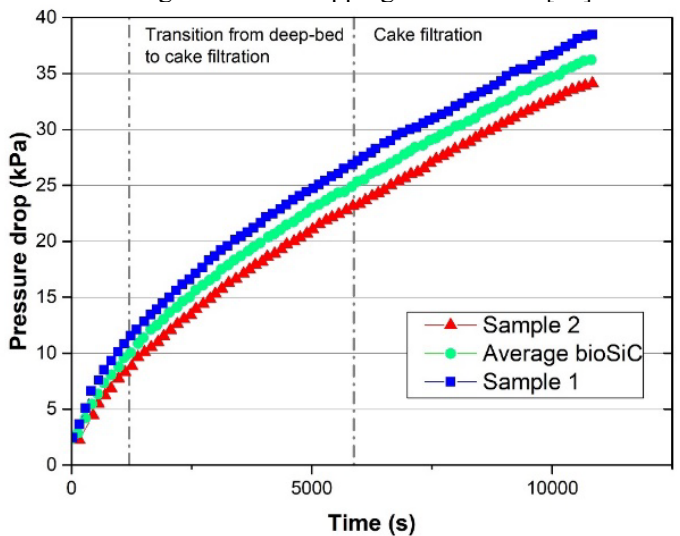

Figure 6: Pressure drop of the wall-flow bioSiC filters [16].

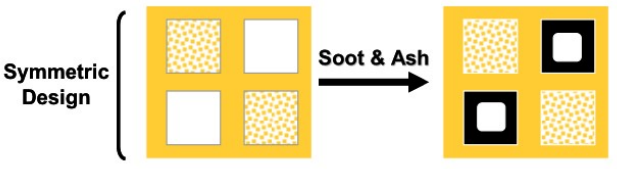

Same amount of soot $\&$ ash

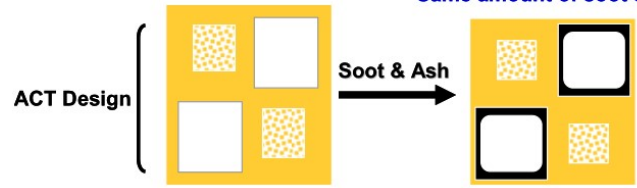

Figure 7. Standard and asymmetric cell technology (ACT) designs [17].

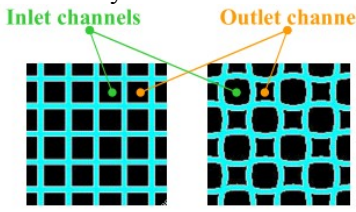

Figure 8. Standard square cell geometry and wavy cell geometry of honeycomb structures [20]. 


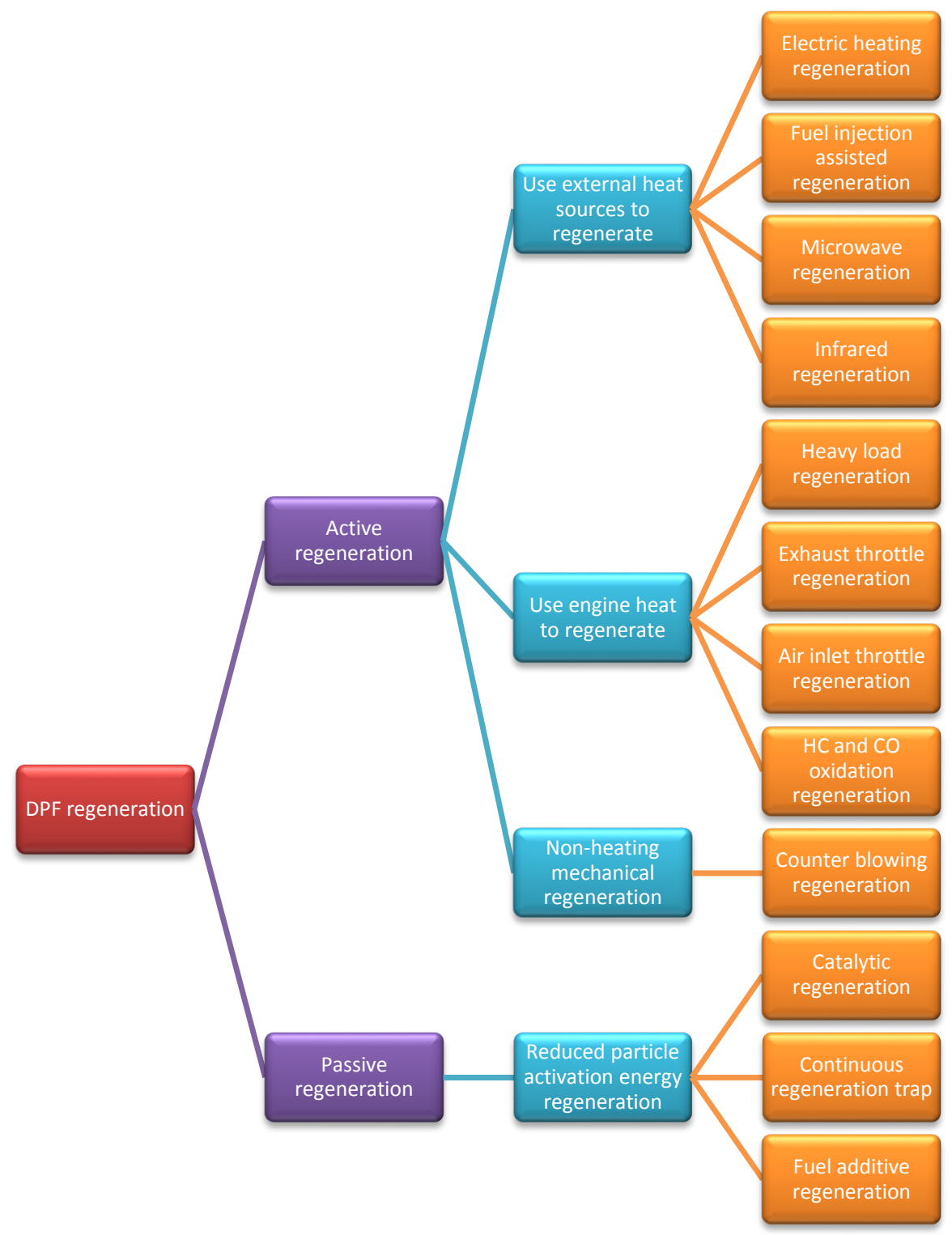

Figure 9. DPF regeneration approaches.

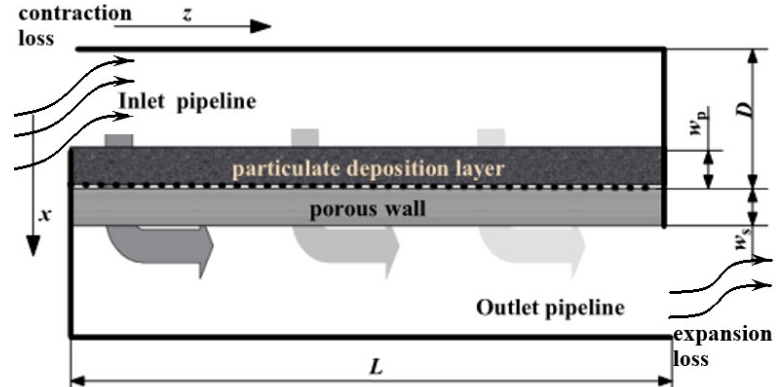

Figure 10. Geometry of inlet and outlet channels of honeycomb ceramic wall-flow monolith [30]. 


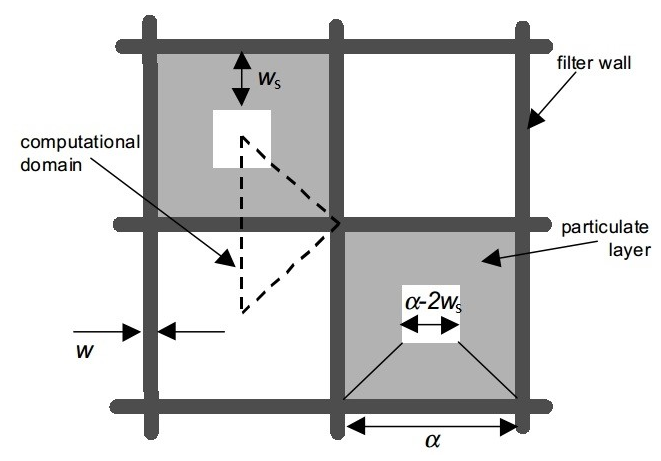

Figure 11. Loaded DPF channel section [33].

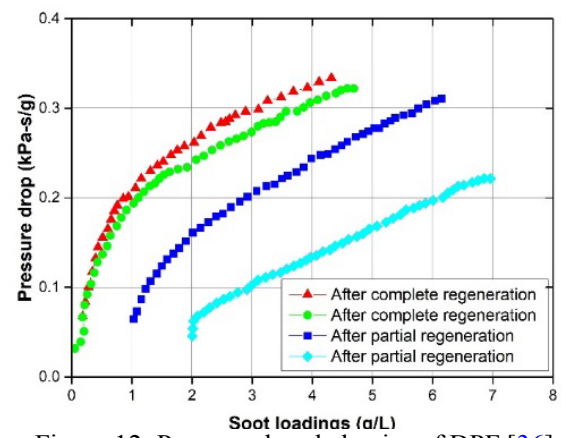

Figure 12. Pressure drop behavior of DPF [36].

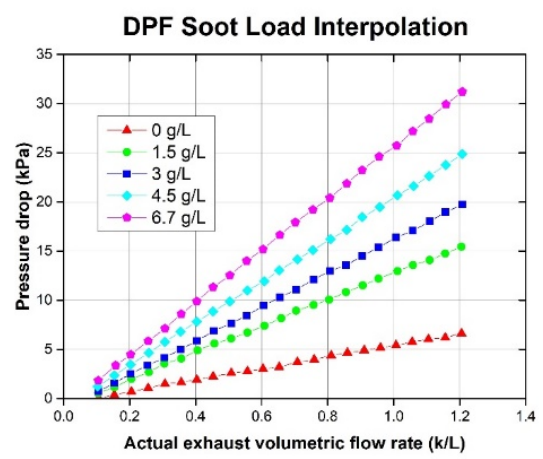

Figure 13. Pressure Drop, Volumetric Flow and Soot Load in the DPF Relationship [37].

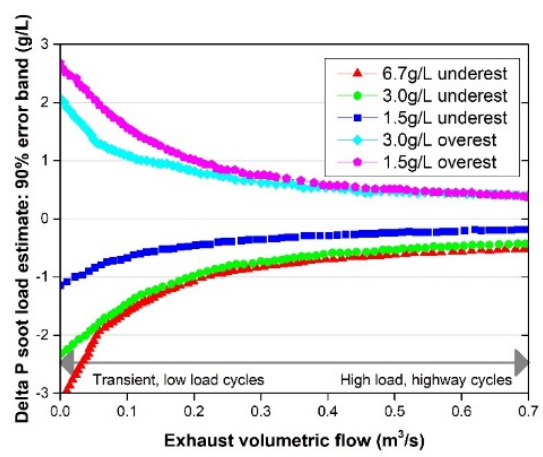

Figure 14. DPF Pressure Drop Based Soot Load Estimate; 90\% Error Bands as a Function of Exhaust Volume Flow [37]. 


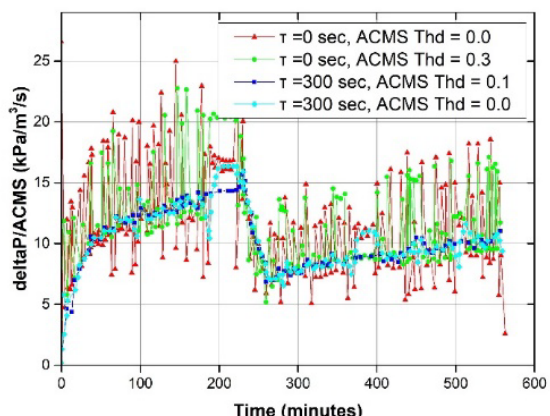

Figure 15. DPF Restriction Signal Processing [37].
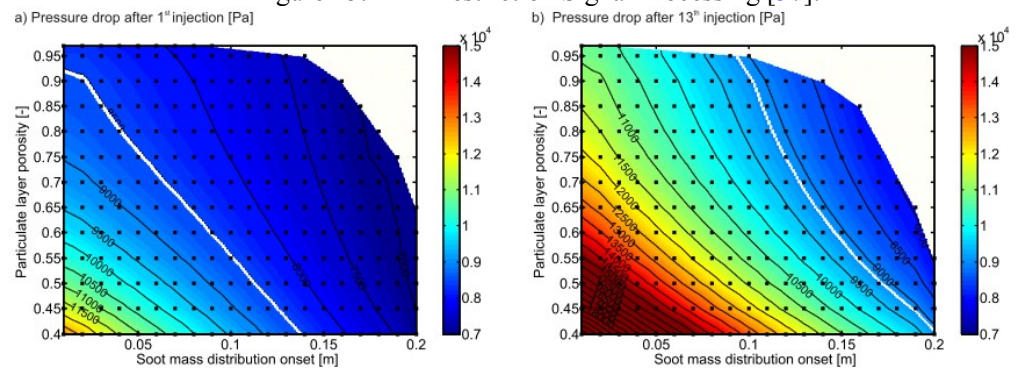

Figure 16. DPF pressure drop as a function of the particulate layer porosity and the soot mass distribution onset imposing a linear soot mass distribution [39].

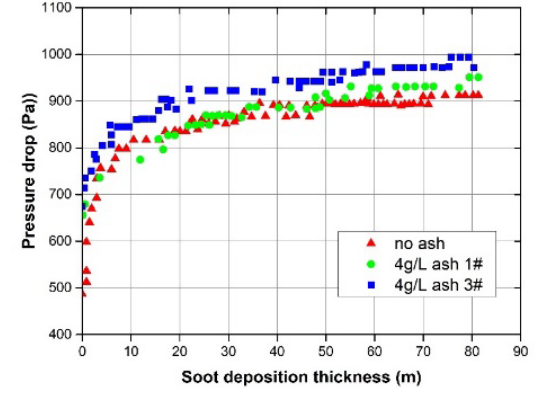

Figure 17. DPF pressure drop as a function of the particulate layer porosity and the soot mass distribution onset imposing a linear soot mass distribution [42]. $m_{i n}=1$

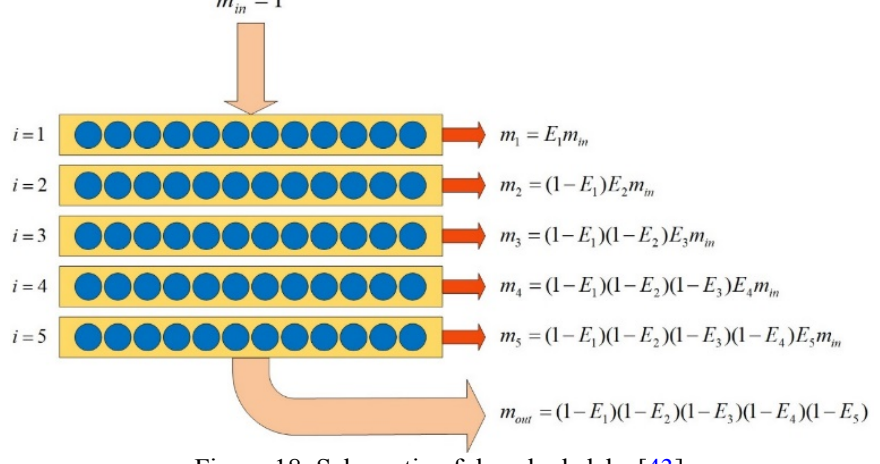

Figure 18. Schematic of deep bed slabs [43]. 


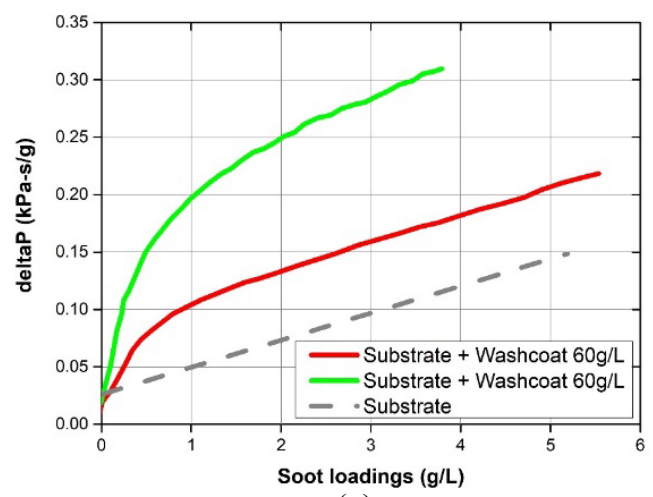

(a)

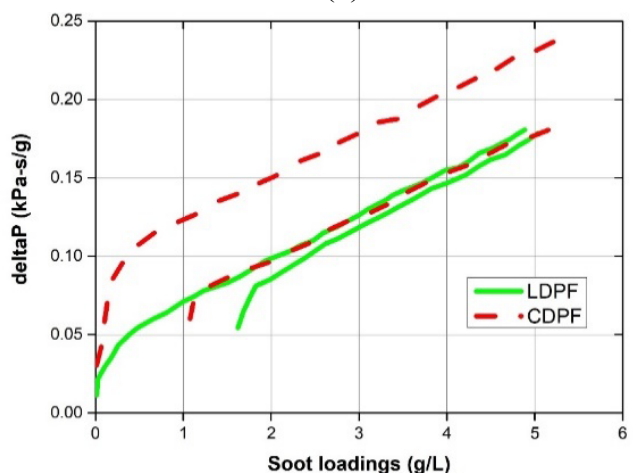

(b)

Figure 19. (a) Influence of washcoat amount on pressure drop; (b) Comparison of estimation accuracy of linear DPF(LDPF) and CDPF [36].

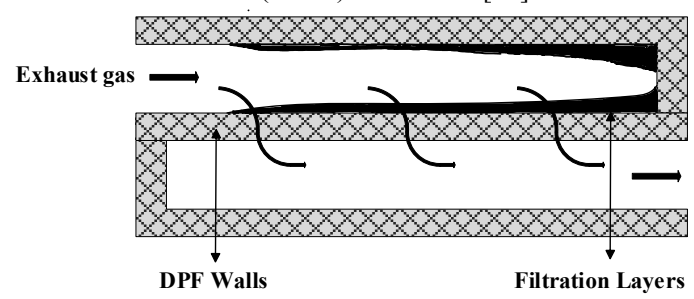

Figure 20. Schematic image of concept of filtration layers technology [26].

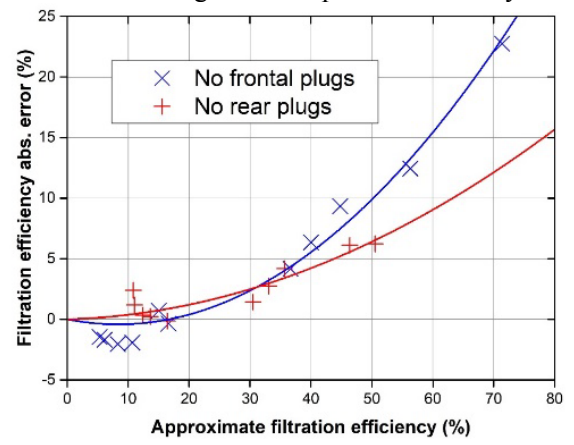

(a) 


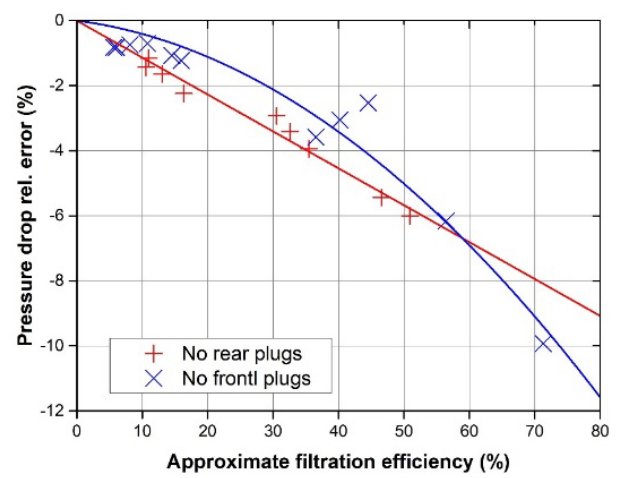

(b)

Figure 21. Correlation of approximate filtration efficiency to (a) approximate filtration efficiency filtration efficiency error and (b) pressure drop error [45].

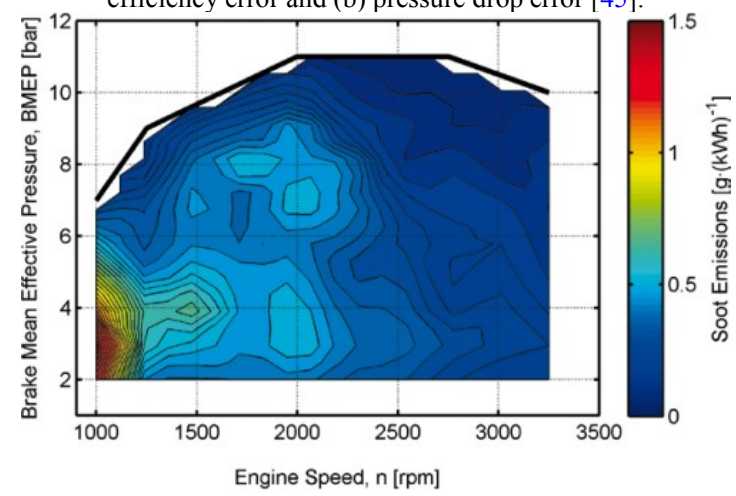

Figure 22. Soot map of a typical LDD engine determined with an AVL Micro Soot Sensor [60].

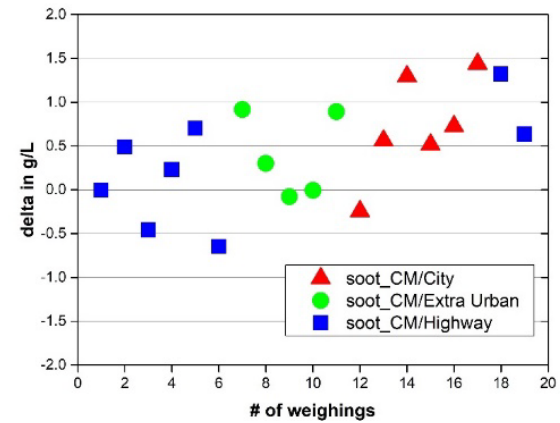

Figure 23. Results for the combination of all 3 models (soot CM) /positive values represent underestimation [59]. 


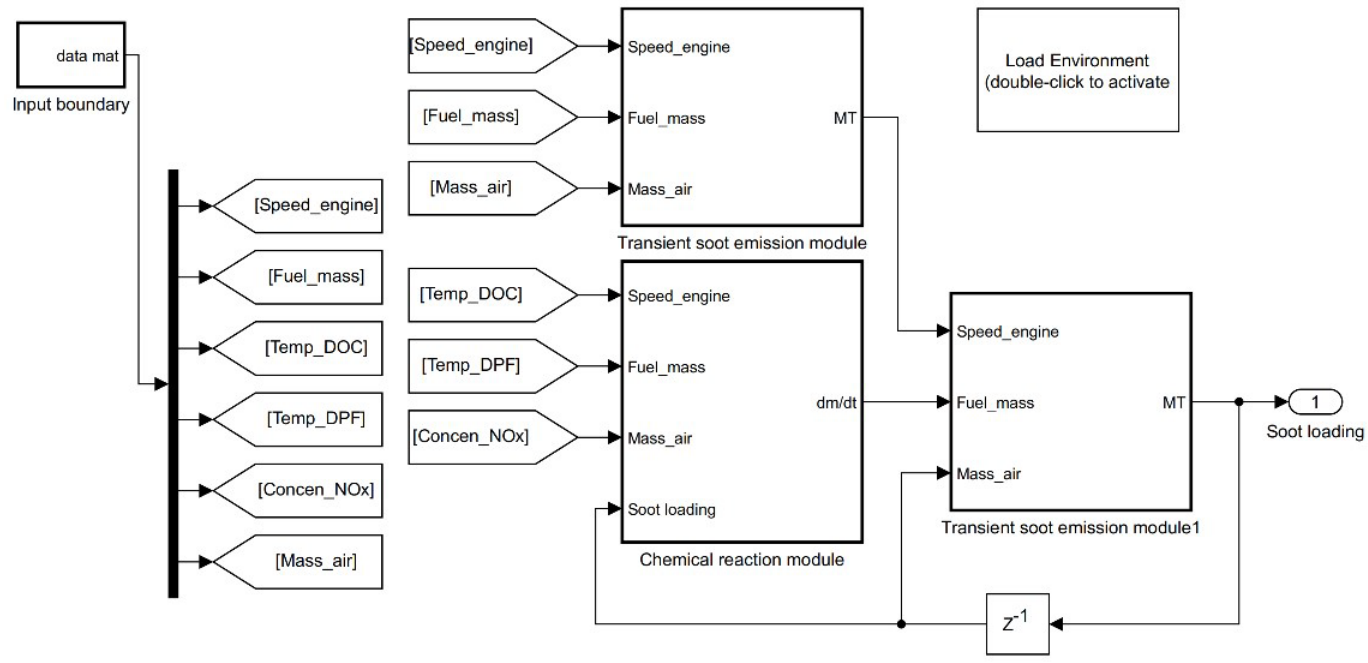

Figure 24. Simulation model of DPF soot loading [62].

Engine out soot emission model

Engine out

NOx emission model
Figure 25. Diagram of mass balance based soot load estimation [63].

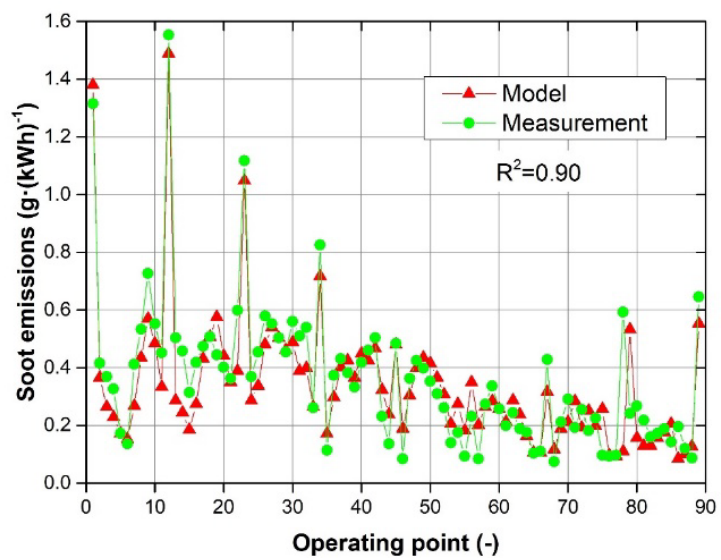

(a) 


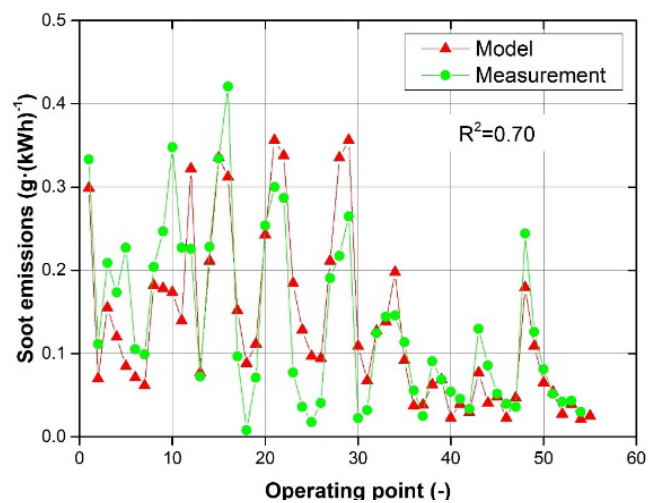

(b)

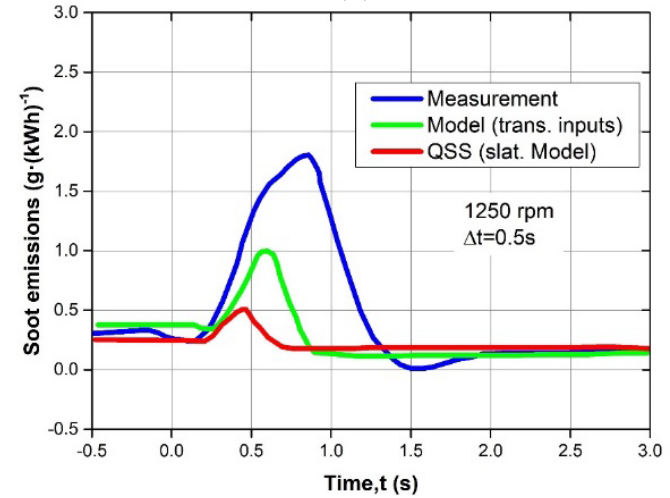

(c)

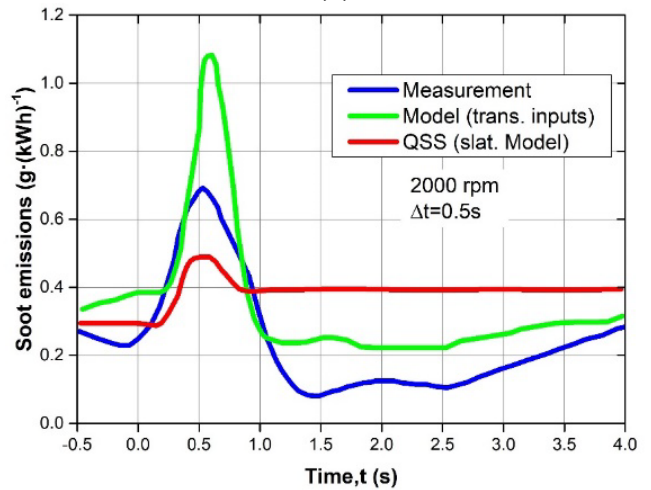

(d)

Figure 26. (a) Emissions in steady state (engine one, reference fuel); (b) Emissions in steady state (engine one, fuel two); (c) Emissions in transient state at $1250 \mathrm{rpm}, \Delta \mathrm{t}=0.5 \mathrm{~s}$; (d) Emission s in transient state at $2000 \mathrm{rpm}$,

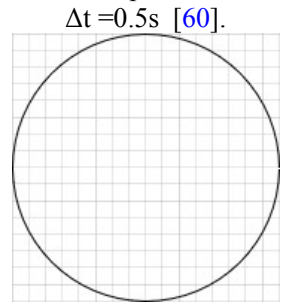

Figure 27. A $16 * 16$ square pixel grid used to display the permittivity distribution image [67]. 


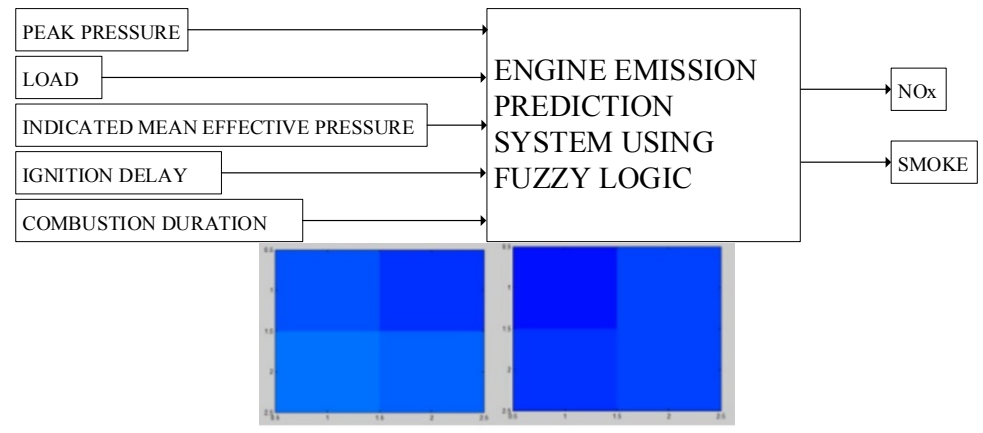

(a)

(b)

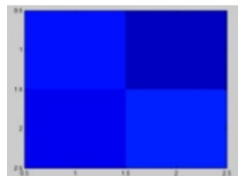

(c)

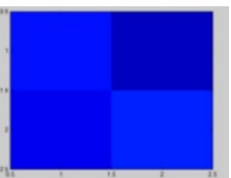

(d)

Figure 28. (a) DPF 0 fill; (b) DPF 25\% fill; (c) DPF 50\% fill; (d) DPF 75\% fill [67].

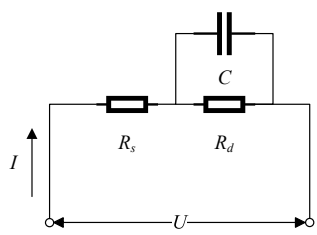

Figure 29. Diesel particulate filter equivalent circuit model [53].

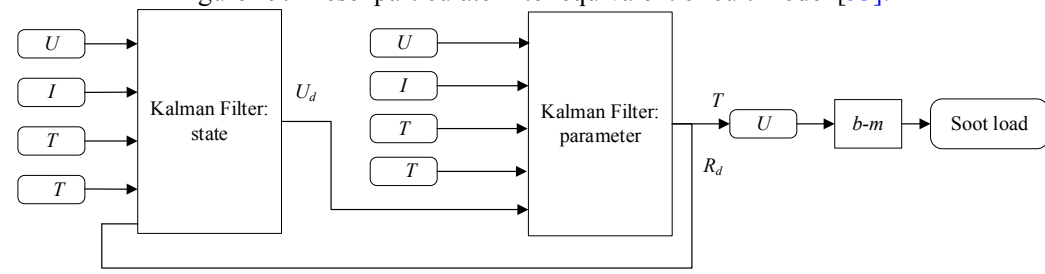

Figure 30. Online estimation process of the soot load [53].

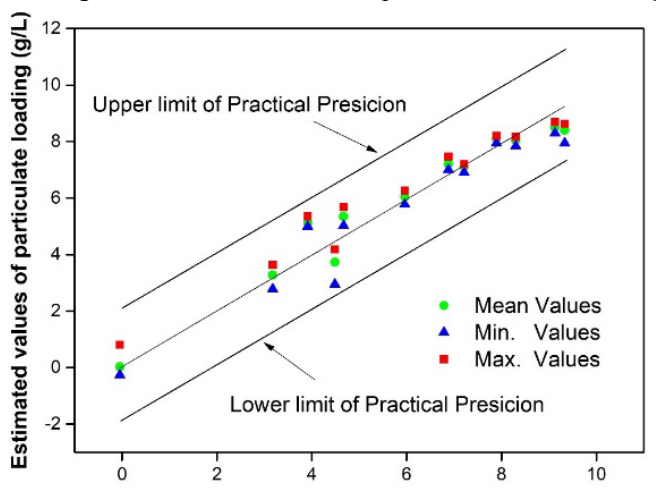

Real values of particulate loading (g/L)

Figure 31. Precision of estimated particulate loading [76].

Figure 32. System inputs and outputs [77]. 


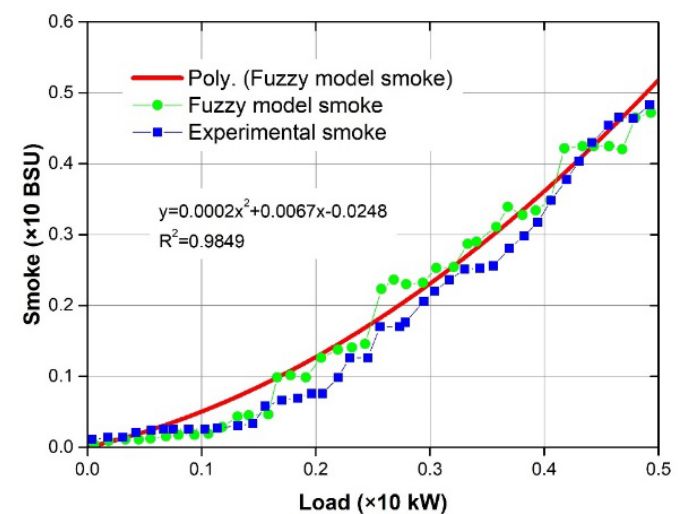

Figure 33. Regression analysis for prediction of smoke [77].

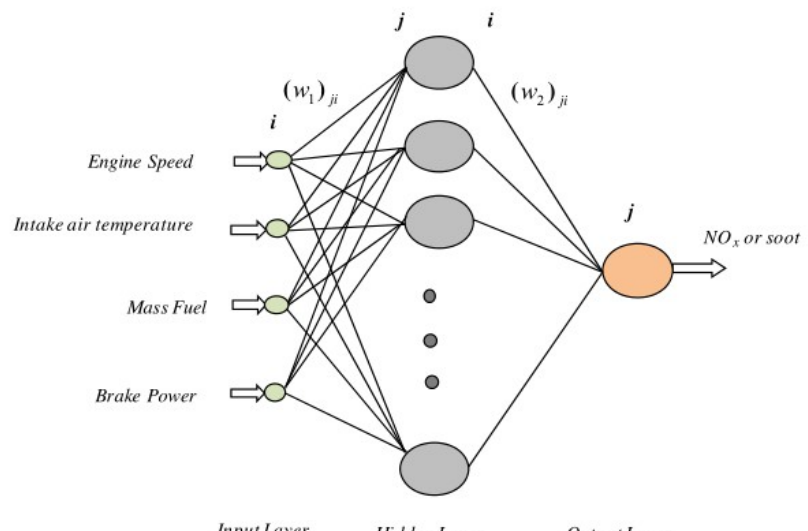

Input Layer Hidden Layer Output Layer

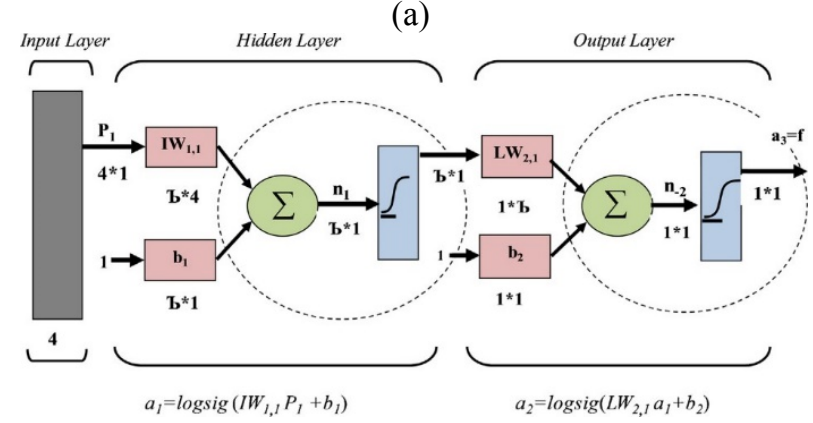

(b)

Figure 34. (a) Simple structure of the used ANN; (b) Detailed structure of the used ANN [79]. 


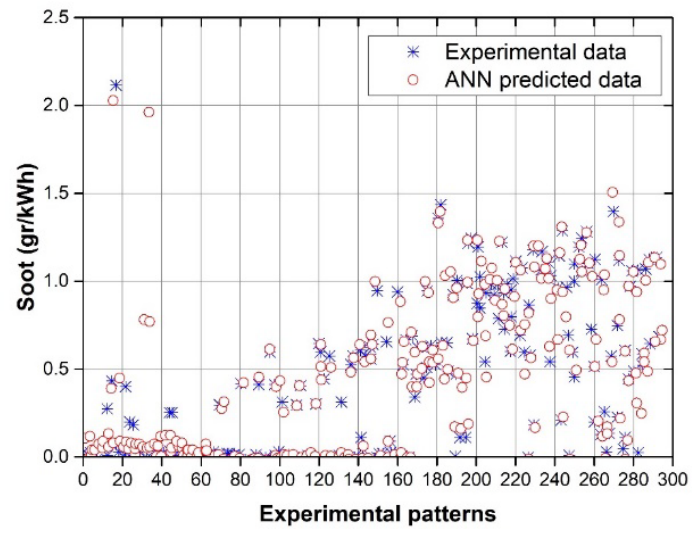

Figure 35. Comparison between the predicted and measured soot emission for different operating conditions [79].

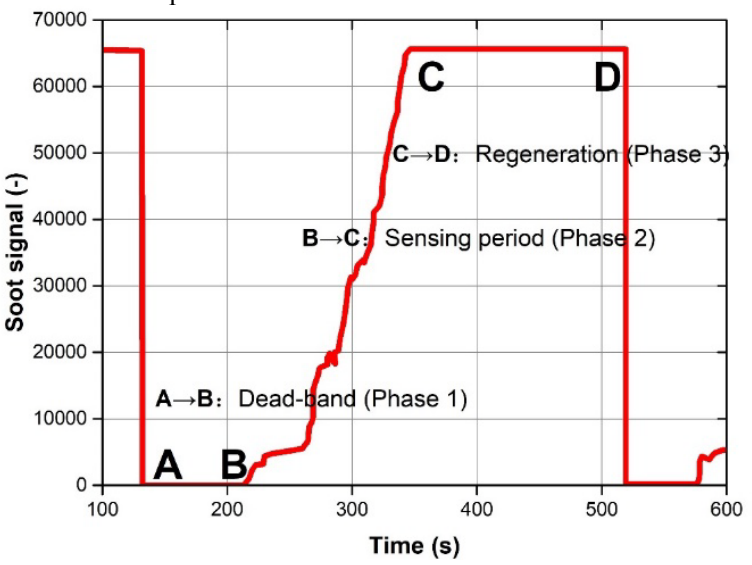

Figure 36. Typical resistive sensor signal and phases of operation [80].

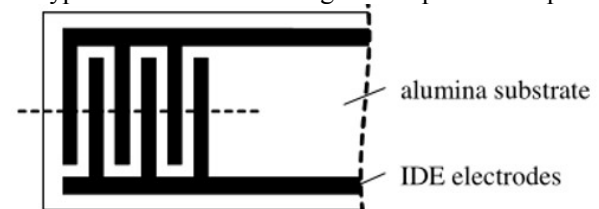

(a)

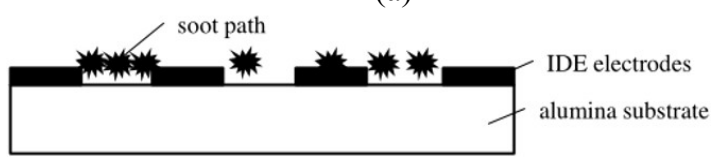

(b)

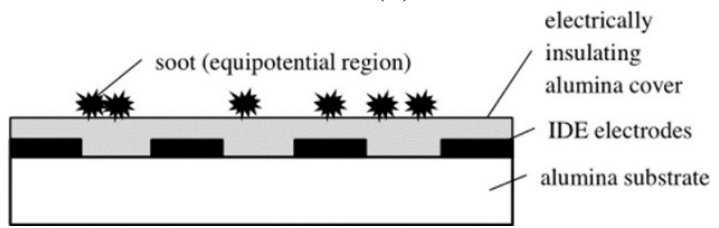

(c)

Figure 37. (a) Sketch of the interdigital electrode design (top view) ; (b) Schematic cross-section of the sensor setup for the conductometric type principle (soot deposition on the sensor surface led to a decreased resistance between the electrodes); (c) Schematic cross-section of the sensor setup for the capacitive type principle (soot deposition on the sensor surface affected the electrical field distribution and therefore affected the capacitance)

[82]. 


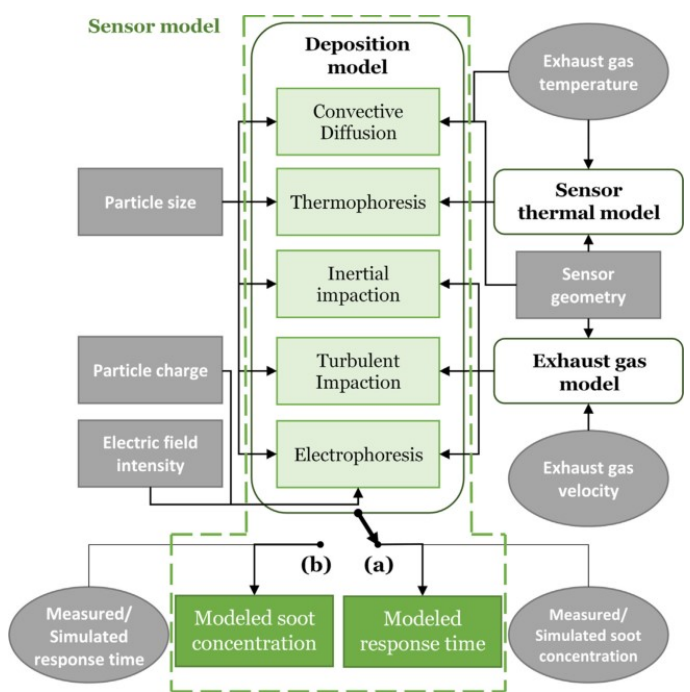

Figure 38. The soot deposition model of the sensor [80].

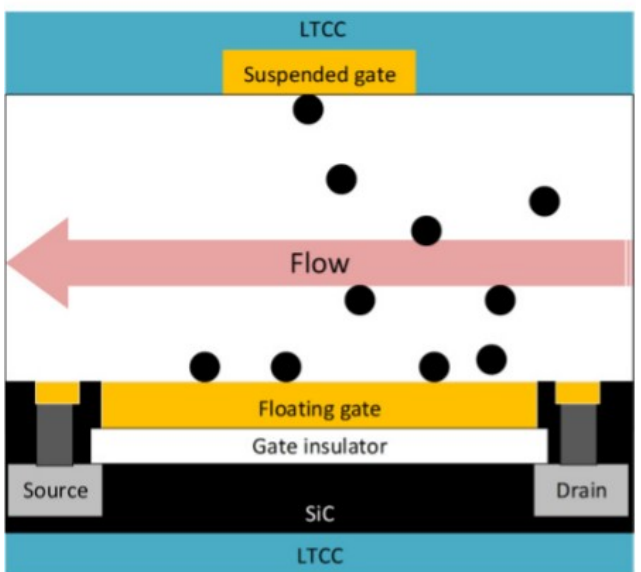

Figure 39. Schematic cross-section of the SiC MOSFET soot sensor [89].

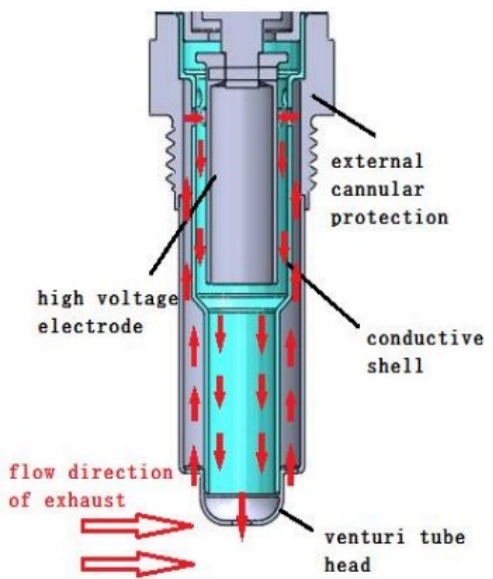

Figure 40. Dimensional structure of the leakage current sensor [91]. 


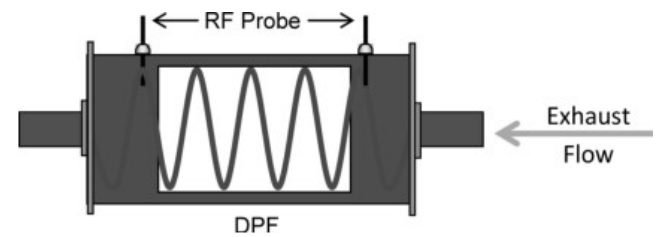

Figure 41. RF measurement system configuration [66].
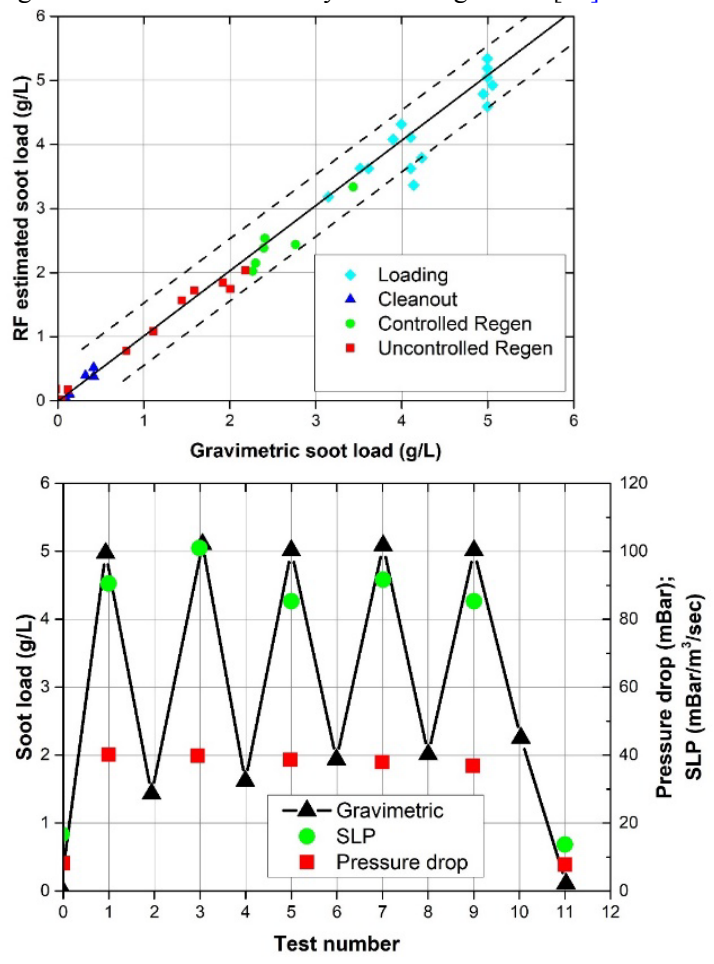

(b)

Figure 42. (a) RF soot load measurement for the heavy-duty engine setup; (b) Comparison of gravimetric and SLP soot load estimation for heavy duty uncontrolled regeneration tests. At low flow conditions, such as those during idle, accurate pressure drop measurements were unavailable [66]. 